\title{
Mathematical Modeling for Water Quality Management under Interval and Fuzzy Uncertainties
}

\author{
J. Liu, Y. P. Li, and G. H. Huang \\ MOE Key Laboratory of Regional Energy Systems Optimization, Resources and Environmental Research Academy, \\ North China Electric Power University, Beijing 102206, China
}

Correspondence should be addressed to Y. P. Li; yongping.li33@gmail.com

Received 4 October 2013; Accepted 29 November 2013

Academic Editor: X. S. Qin

Copyright (C) 2013 J. Liu et al. This is an open access article distributed under the Creative Commons Attribution License, which permits unrestricted use, distribution, and reproduction in any medium, provided the original work is properly cited.

In this study, an interval fuzzy credibility-constrained programming (IFCP) method is developed for river water quality management. IFCP is derived from incorporating techniques of fuzzy credibility-constrained programming (FCP) and intervalparameter programming (IPP) within a general optimization framework. IFCP is capable of tackling uncertainties presented as interval numbers and possibility distributions as well as analyzing the reliability of satisfying (or the risk of violating) system's constraints. A real-world case for water quality management planning of the Xiangxi River in the Three Gorges Reservoir Region (which faces severe water quality problems due to pollution from point and nonpoint sources) is then conducted for demonstrating the applicability of the developed method. The results demonstrate that high biological oxygen demand (BOD) discharge is observed at the Baishahe chemical plant and Gufu wastewater treatment plant. For nonpoint sources, crop farming generates large amounts of total phosphorus (TP) and total nitrogen (TN). The results are helpful for managers in not only making decisions of effluent discharges from point and nonpoint sources but also gaining insight into the tradeoff between system benefit and environmental requirement.

\section{Introduction}

Water is one of the most essential constituents for the human life, which is crucial to various socioeconomic issues such as industrial production, agricultural activity, environmental protection, and regional sustainability. In recent years, especially in China, degradation of water quality due to point and nonpoint source pollutions has become one of the most pressing environmental concerns. According to the 2010 Report on Water Environmental Quality of China, approximately $33.8 \%$ of the monitored river water (204 rivers with 409 monitoring stations) is in the worst two categories of water quality classification system (i.e., no longer fishable and of questionable agricultural value); around $53.8 \%$ of the assessed lakes and reservoirs are subject to different degrees of eutrophication [1]. Under such a circumstance, water quality management is an essential task for preserving valuable water resources and facilitating sustainable socioeconomic development in watershed systems [2]. In fact, water quality planning efforts are complicated with a variety of uncertainties, which may be derived from the random characteristics of natural processes (i.e., precipitation and climate change) and stream conditions (i.e., stream flow, water supply, and point/nonpoint source pollution), the errors in estimated modeling parameters, and the vagueness of system objectives and constraints. In general, the system objectives are often associated with a number of socioeconomic and ecological factors such as economic return, environmental protection, and ecological sustainability, while the constraints are related to pollutant discharges, soil losses, resources availabilities, environmental requirements, and policy regulations. Moreover, these uncertainties may be further amplified by not only interactions among various uncertain and dynamic impact factors, but also their associations with economic implications of violated environmental requirements [3].

Fuzzy mathematic programming (FMP), based on fuzzy sets theory, can facilitate the analysis of system associated with uncertainties being derived from vagueness or fuzziness [4]. FMP method is suitable for situation when the uncertainties cannot be expressed as probability density functions (PDFs), such that adoption of fuzzy membership 
functions becomes an attractive alternative [5]. Previously, a number of FMP methods were developed for water quality management [5-15]. For example, Julien [6] investigated the application of a fuzzy possiblistic programming to address imprecise parameters which were represented by possibility distributions in water quality decision-making problems. Mujumdar and Sasikumar [8] formulated a fuzzy flexible optimization model for dealing with the system's fuzzy goal and constraints in a water quality management problem. Nie et al. [12] proposed a fuzzy robust optimization model for water quality management of an agricultural system to deal with uncertainties expressed as fuzzy membership functions in both left- and right-hand-side coefficients (of the model's constraints). Maeda et al. [13] employed a fuzzy flexible optimization model which involved fuzzy set theory to express vagueness in constraints and objectives in river water quality management problems. Liu et al. [15] developed a two-stage fuzzy robust programming model for water quality management to address fuzzy parameters which were represented by possibility distributions in the left- and righthand sides of the constraints.

Generally, FMP methods can be classified into three categories in view of the forms of uncertainties: (i) fuzzy flexible programming, (ii) robust programming, and (iii) fuzzy possibilistic programming. In detail, fuzzy flexible programming can deal with decision problems under fuzzy goal and constraints; however, it has difficulties in tackling ambiguous coefficients of the objective function and constraints. Robust programming improves upon fuzzy flexible programming by allowing fuzzy parameters in the constraints to be represented by possibility distributions. However, the main limitations of this method remain in its difficulties in tackling uncertainties in a nonfuzzy decision space. In fuzzy possibilistic programming, fuzzy parameters that are regarded as possibility distributions are introduced into the modeling frameworks. It can handle ambiguous coefficients in the left- and right-hand sides of the constraints and in the objective function.

Fuzzy credibility-constrained programming (FCP) is a computationally efficient fuzzy possibilistic programming approach that relies on mathematical concepts (i.e., the expected value of a fuzzy number and the credibility measure) and can support different kinds of fuzzy members such as triangular and trapezoidal forms as well as enabling the decision maker to satisfy some constraints in at least some given confidence levels [16]. When the credibility value of a fuzzy event reaches 1 , the fuzzy event will certainly occur; when the credibility value of a fuzzy event reaches 0 , the fuzzy event will not occur. For example, with respect to water quality management, if the allowable total phosphorus (TP) discharges are 7.0, 7.6, and $8.2 \mathrm{~kg} / \mathrm{day}$, and the amount of actual discharge may be $7.8 \mathrm{~kg} / \mathrm{day}$, then the credibility degree of the event, wherein the total phosphorus discharge can satisfy the river's self-purification capacity, would be 0.33; the credibility degree of its complement event (water pollution occur) would be 0.67 . No feature of fuzzy sets would be missing by using credibility measure $[16,17]$. However, the main limitation of FCP lies within its deterministic coefficients for the objective function, leading to potential losses of valuable uncertain information; besides, when many uncertain parameters are expressed as fuzzy sets, interactions among these uncertainties may lead to serious complexities, particularly for large-scale practical problems [18]. In fact, in water quality management problems, uncertainty is an inherent component of any economic analysis, particularly those (e.g., effluent trading programs) associated with environmental policy and project appraisal [19]. For example, one major characteristic of nonpoint source pollution that differs from point source pollution is imperfect knowledge about pollutant loadings; the crop productivity and cost benefit coefficients are easier to be presented as intervals than by membership functions. Interval-parameter programming (IPP) is an alternative for handling uncertainties in the model's left- and/or right-hand sides as well as those that cannot be quantified as membership or distribution functions, since interval numbers are acceptable as its uncertain inputs [20].

Therefore, the objective of this study is to develop an inexact fuzzy credibility-constrained programming (IFCP) method for water quality management, through coupling fuzzy credibility-constrained programming (FCP) with interval-parameter programming (IPP). The main advantage of IFCP is that it can effectively handle uncertain parameters expressed as both fuzzy sets and interval values in the objective function and constraints. IFCP would not lead to serious complexities in its solution process, and it is applicable to large-scale practical problems. Then, the developed IFCP method is applied to a real-world case of water quality management of the Xiangxi River, which faces severe water quality problems due to point and nonpoint source pollution. The results obtained can help decision makers to generate alternatives for industrial production scale, water supply, cropped area, livestock husbandry size, and manure/fertilizer application rate, with consideration of river water quality management.

The paper will be organized as follows: Section 2 describes the development process of the IFCP; Section 3 provides a case study of river water quality management; Section 4 presents result analysis and discussion; Section 5 draws some conclusions and extensions.

\section{Methodology}

When coefficients in the constraints are ambiguous and can be expressed as possibility distributions, the problem can be formulated as a fuzzy credibility-constrained programming (FCP) model as follows:

$$
\operatorname{Max} f=\sum_{j=1}^{n} c_{j} x_{j},
$$

subject to:

$$
\begin{aligned}
& \operatorname{Cr}\left\{\sum_{j=1}^{n} a_{i j} x_{j} \leq \widetilde{b}_{i}\right\} \geq \lambda_{i}, \\
& x_{j} \geq 0, \quad i=1,2, \ldots, n,
\end{aligned}
$$


where $x=\left(x_{1}, x_{2}, \ldots, x_{n}\right)$ is a vector of nonfuzzy decision variables, $c_{j}$ are benefit coefficients, $a_{i j}$ are technical coefficients, and $\widetilde{b}_{i}$ are right-hand-side coefficients. Some or all of these coefficients can be fuzzy numbers. $\mathrm{Cr}$ is the credibility measure which is firstly proposed and was widely used in many research areas [16]. Let $\xi$ be a fuzzy variable with membership function $\mu$, and let $r$ be real numbers. The credibility measure can be defined as follows [17]:

$$
\operatorname{Cr}\{\xi \leq r\}=\frac{1}{2}\left(\sup _{x \leq r} \mu(x)+1-\sup _{x>r} \mu(x)\right) .
$$

Noteworthy, since $\operatorname{Pos}\{\xi \leq r\}=\sup _{x \leq r} \mu(x)$ and $\operatorname{Nec}\{\xi \leq$ $r\}=1-\sup _{x>r} \mu(x)$, the credibility measure can be defined as follows:

$$
\operatorname{Cr}\{\xi \leq r\}=\frac{1}{2}(\operatorname{Pos}\{\xi \leq r\}+\operatorname{Nec}\{\xi \leq r\}) .
$$

Similar to the probability measure,

$$
\operatorname{Cr}\{\xi \leq r\}+\operatorname{Cr}\{\xi>r\}=1 .
$$

Consider a triangular fuzzy variable since it is the most popular possibility distribution, the fuzzy variable $\xi$ fully determined by the triplet $(\underline{t}, t, \bar{t})$ of crisp numbers with $\underline{t}<$ $t<\bar{t}$ whose membership function is given by

$$
\mu(r)= \begin{cases}\frac{r-\underline{t}}{t-\underline{t}}, & \text { if } \underline{t} \leq r \leq t, \\ \frac{r-\bar{t}}{t-\bar{t}}, & \text { if } t \leq r \leq \bar{t} \\ 0, & \text { otherwise. }\end{cases}
$$

Based on this membership function, credibility of $r \leq \xi$ can be expressed by

$$
\operatorname{Cr}\{r \leq \xi\}= \begin{cases}1, & \text { if } r \leq \underline{t}, \\ \frac{2 t-\underline{t}-r}{2(t-\bar{t})}, & \text { if } \underline{t} \leq r \leq t, \\ \frac{r-\bar{t}}{2(t-\bar{t})}, & \text { if } t \leq r \leq \bar{t}, \\ 0, & \text { if } r \geq \bar{t} .\end{cases}
$$

The inverse function of the credibility measure is $\mathrm{Cr}^{-1}(\lambda)=r$, when $\operatorname{Cr}(r \leq \xi)=\lambda$. Normally, it is assumed that a significant credibility level should be greater than 0.5 . Therefore, (6) can be written as

$$
\operatorname{Cr}\{r \leq \xi\}=\frac{2 t-\underline{t}-r}{2(t-\bar{t})} \geq \lambda .
$$

Then, (7) can be transformed into a deterministic constraint as follows:

$$
r \leq t+(1-2 \lambda)(t-\underline{t}) .
$$

The fuzzy credibility-constrained programming (FCP) model can be formulated as follows:

$$
\operatorname{Max} f=\sum_{j=1}^{n} c_{j} x_{j}
$$

subject to

$$
\begin{gathered}
\sum_{j=1}^{n} a_{i j} x_{j} \leq b_{i}+\left(1-2 \lambda_{i}\right)\left(b_{i}-\underline{b}_{i}\right), \\
x_{j} \geq 0, \quad i=1,2, \ldots, n .
\end{gathered}
$$

Obviously, model (9a), (9b), and (9c) can effectively deal with uncertainties in the right-hand sides presented as fuzzy sets when coefficients in the left-hand sides and in the objective function are deterministic. However, in realworld optimization problems, uncertainties may exist in both left- and right-hand sides (of the constraints) as well as objective-function coefficients; moreover, the quality of information that can be obtained is mostly not satisfactory enough to be presented as fuzzy membership functions [2]. For example, economic return, pollutant discharge, and resources availability are easier to be expressed as intervals than membership functions [21]. Since interval-parameter programming (IPP) is useful for addressing uncertainties expressed as interval values in modeling parameters, it can be integrated into the FCP model to deal with uncertainties presented in fuzzy and interval formats. Then, an interval fuzzy credibility-constrained programming (IFCP) can be formulated as follows:

$$
\operatorname{Max} f^{ \pm}=\sum_{j=1}^{n} c_{j}^{ \pm} x_{j}^{ \pm}
$$

subject to

$$
\begin{gathered}
\sum_{j=1}^{n} a_{i j}^{ \pm} x_{j}^{ \pm} \leq b_{i}+\left(1-2 \lambda_{i}^{ \pm}\right)\left(b_{i}-\underline{b}_{i}\right), \\
x_{j}^{ \pm} \geq 0, \quad i=1,2, \ldots, n,
\end{gathered}
$$

where the "-" and "+" superscripts represent the lower- and upper-bounds of interval parameters/variables, respectively. Then, a two-step solution method is proposed for facilitating computations of the IFCP model. The first submodel can be formulated as follows:

$$
\operatorname{Max} f^{+}=\sum_{j=1}^{k_{1}} c_{j}^{+} x_{j}^{+}+\sum_{j=k_{1}+1}^{n} c_{j}^{+} x_{j}^{-},
$$


subject to

$$
\begin{aligned}
& \sum_{j=1}^{k_{1}}\left|a_{i j}\right|^{-} \operatorname{Sign}\left(a_{i j}^{-}\right) x_{j}^{+} \\
& +\sum_{j=k_{1}+1}^{n}\left|a_{i j}\right|^{+} \operatorname{Sign}\left(a_{i j}^{+}\right) x_{j}^{-} \\
& \leq b_{i}+\left(1-2 \lambda_{i}^{-}\right)\left(b_{i}-\underline{b}_{i}\right), \\
& \quad \forall i=1,2, \ldots, m, \\
& x_{j}^{+} \geq 0, \quad j=1,2, \ldots, k_{1}, \\
& x_{j}^{-} \geq 0, \quad j=k_{1}+1, \ldots, n,
\end{aligned}
$$

where $c_{j}^{+}\left(j=1,2, \ldots, k_{1}\right)>0 ; c_{j}^{+}\left(j=k_{1}+1, k_{2}+1, \ldots, n\right)<$ $0 ; \operatorname{Sign}\left(a_{i j}^{ \pm}\right)=-1$ when $a_{i j}^{ \pm}<0 ; \operatorname{Sign}\left(a_{i j}^{ \pm}\right)=1$ when $a_{i j}^{ \pm}>$ $0 ; \lambda_{i}^{-}$is the lower bound of the credibility level value. The optimal solutions of the first submodel would be $x_{\text {jopt }}^{+}(j=$ $\left.1,2, \ldots, k_{1}\right)$ and $x_{\text {jopt }}^{-}\left(j=k_{1}+1, k_{2}+1, \ldots, n\right)$. In the second step, the submodel corresponding to $f^{-}$can be formulated:

$$
\operatorname{Max} f^{-}=\sum_{j=1}^{k_{1}} c_{j}^{-} x_{j}^{-}+\sum_{j=k_{1}+1}^{n} c_{j}^{-} x_{j}^{+},
$$

subject to

$$
\begin{gathered}
\sum_{j=1}^{k_{1}}\left|a_{i j}\right|^{+} \operatorname{Sign}\left(a_{i j}^{+}\right) x_{j}^{-}+\sum_{j=k_{1}+1}^{n}\left|a_{i j}\right|^{-} \operatorname{Sign}\left(a_{i j}^{-}\right) x_{j}^{+} \\
\leq b_{i}+\left(1-2 \lambda_{i}^{+}\right)\left(b_{i}-\underline{b}_{i}\right), \forall i=1,2, \ldots, m, \\
0 \leq x_{j}^{-} \leq x_{j \mathrm{opt}}^{+}, \quad j=1,2, \ldots, k_{1}, \\
x_{j}^{+} \geq x_{\text {jopt }}^{-}, \quad j=k_{1}+1, \ldots, n .
\end{gathered}
$$

The optimal solutions of model (11a), (11b), (11c), and (11d) would be $x_{\text {jopt }}^{-}\left(j=1,2, \ldots, k_{1}\right)$ and $x_{\text {jopt }}^{+}\left(j=k_{1}+1, k_{2}+\right.$ $1, \ldots, n)$ can be obtained. Through integrating the solutions of the two submodels, the solution for the objective-function value and decision variables can be obtained as follows:

$$
\begin{aligned}
f_{\mathrm{opt}}^{ \pm} & =\left[f_{\mathrm{opt}}^{-}, f_{\mathrm{opt}}^{+}\right], \\
x_{\text {jopt }}^{ \pm} & =\left[x_{\text {jopt }}^{-}, x_{\text {jopt }}^{+}\right] .
\end{aligned}
$$

\section{Case Study}

The Xiangxi River (which ranges in longitude from $110^{\circ} 25^{\prime}$ to $111^{\circ} 06^{\prime} \mathrm{E}$ and in latitude from $30^{\circ} 57^{\prime}$ to $31^{\circ} 34^{\prime} \mathrm{N}$ ) is located at $40 \mathrm{~km}$ upstream of the Three Gorges Reservoir [22]. It is $94 \mathrm{~km}$ long with a catchment area of $3099 \mathrm{~km}^{2}$, and its elevation generally ranges from $154 \mathrm{~m}$ to $3000 \mathrm{~m}$. It is located in the subtropical continental monsoon climate zone, with an annual temperature of $15.6^{\circ} \mathrm{C}$ (from 1961 to 2004) and the long-term annual mean runoff depth of $688 \mathrm{~mm}$ [23]. Moreover, it is one of the rainiest centers in the west of Hubei province, with an average annual precipitation ranges from $900 \mathrm{~mm}$ to $1200 \mathrm{~mm}$. The temporal precipitation of this basin is uneven, which varies largely among different seasons. For example, more than $41 \%$ precipitation occurs in June to August, and the rainfall in the spring, autumn, and winter seasons occupy $28 \%, 26 \%$, and $5 \%$ of the total precipitation per year, respectively. There are plenty of mineral resources (i.e., phosphate ore, coal, pyrite, and granite), where the reserve of phosphorite is among the top three in China, which reaches 357 million $t$ (i.e., tonne) [1]. Relying on these advantages, the number of phosphorus mining companies and related chemical plants are increasing along the banks of the Xiangxi River. Besides, multiple crops such as rice, maize, wheat, citrus, tea, potato, and vegetable are cultivated in the catchment since the land-use patterns are diverse, and the tillable area land is approximately $294.5 \mathrm{~km}^{2}$. In addition, pig, ox, sheep, and domestic fowl are the main live stocks in animal husbandry. The main pattern is scattered livestock breeding instead of large-scale standardized breeding.

Currently, water quality problems due to point and nonpoint source pollution discharges become more and more challenging in this catchment. Main point sources include five chemical plants (i.e., GF, BSH, PYK, LCP, and XJLY), six phosphorus mining companies (i.e., XL, XH, XC, GP, JJW, and SJS), and four wastewater treatment plants (WTPs) (i.e., Gufu, Nanyang, Gaoyang, and Xiakou), while four agricultural zones (AZ1 to AZ4) are the main nonpoint sources due to the application of manure/fertilizer. These point and nonpoint sources scatter along a length of about $51 \mathrm{~km}$ river stretch which is segmented into five reaches, and the reaches are marked as I to $\mathrm{V}$. The main water quality problems include (i) the immoderate discharge of high-concentration phosphorus-containing wastewater and industrial soil wastes (i.e., chemical wastes, slags, and tailings) far exceed what can be decomposed by self-purification (according to the field investigation, $23.89 t$ of phosphorus enters downstream of the Xiangxi River); (ii) high potential for generating soil erosion and surface runoff due to the special geography and heavy rainfall (i.e., the average erosion modulus reaches 6,488 $\mathrm{t} /\left(\mathrm{km}^{2} \cdot \mathrm{a}\right)$ in Xiangshan County in this catchment); (iii) large amounts of nutrient pollutants (in terms of phosphorus and nitrogen) in livestock wastewater and wastes (from pig, ox, sheep, and domestic fowl breeding) are drained into the river by direct discharge or in rainfall. In such a circumstance, decision makers should seek to develop a sound pollution control plan to ameliorate the current situation of the water environment since it is infeasible and technical impossible to ensure zero emission of pollutants.

In this study, the planning horizon is one year. Moreover, since some crops should be grown in dry season, while some other crops should be cultivated in wet season, two periods are chosen to cover the planning horizon. The first period 
is from June to October (i.e., dry season), and the second period is from November to May of the next year (i.e., wet season). The objective is to maximize the net system benefit subject to the environmental requirements under uncertainty over the planning horizon. Policies in terms of the related human activities (i.e., industrial, municipal, and agricultural activities) and the pollutant discharges (from fifteen point and four nonpoint sources) are critical for ensuring a maximum system benefit and a safe water quality [24]. Based on field investigations and related literatures, biological oxygen demand (BOD), total nitrogen (TN), and total phosphorus (TP) are selected as water quality indicators $[1,25]$. To develop the local economy in a sustainable manner, pollutant discharge should be controlled by setting the thresholds for TP, TN, and BOD discharge in each reach [26]. However, human-induced imprecision in acquiring these thresholds (i.e., lack of available data and biased judgment) make it more complicate.

On the other hand, uncertainties in the study system include the following: (a) cost of wastewater treatment, manure, and fertilizer purchase are associated with many uncertain factors, which are expressed as interval numbers (e.g., an interval of $[30,35]$ RMB¥/t is denoted as cost of manure purchase of AZ1 in dry season); (b) the BOD and TP treatment efficiencies of wastewater in WTPs and chemical plants are related to operating conditions of the treatment facilities, which cannot be obtained as deterministic numbers (e.g., an interval of $[0.89,0.92]$ is denoted as treatment efficiencies of wastewater in Xiakou WTP); (c) nonpoint source losses of nitrogen and phosphorus from agricultural zones fluctuate dynamically due to variability in soil erosion (corresponding to solid-phase nitrogen) and surface runoff (corresponding to dissolved nitrogen) (e.g., average soil loss from AZ1 planted with citrus in dry season would be $[20.49,22.82] \mathrm{t} / \mathrm{ha}$ ), and runoff from AZ1 planted with citrus in dry season would be $[78.07,96.50] \mathrm{mm})$; (d) the amount of fertilizer and manure applications may vary with the soil fertility to meet the nutrient demands of each crop (i.e., nitrogen and phosphorus); (e) energy and digestible protein demands of human and animals are determined by crops' yield (e.g., yield of citrus planted in AZ1 during dry season would be $[10.3,12.6] \mathrm{t} / \mathrm{ha})$. Therefore, based on the IFCP method developed in Section 2, the study problem can be formulated as:

$$
\begin{aligned}
\operatorname{Max} f^{ \pm}= & \sum_{i=1}^{5} \sum_{t=1}^{2} L_{t} \cdot \mathrm{BC}_{i t}^{ \pm} \cdot \mathrm{PLC}_{i t}^{ \pm}+\sum_{s=1 t=1}^{4} \sum_{t}^{2} L_{t} \cdot \mathrm{BW}_{s t}^{ \pm} \cdot \mathrm{QW}_{s t}^{ \pm} \\
& +\sum_{p=1}^{6} \sum_{t=1}^{2} L_{t} \cdot \mathrm{BP}_{p t}^{ \pm} \cdot \mathrm{PLM}_{p t}^{ \pm} \\
& +\sum_{r=1}^{4} \mathrm{BL}_{r}^{ \pm} \cdot \mathrm{NL}_{r}^{ \pm}+\sum_{j=1}^{4} \sum_{k=1}^{9} \sum_{t=1}^{2} \mathrm{CY}_{j k t}^{ \pm} \cdot \mathrm{BA}_{j k t}^{ \pm} \cdot \mathrm{PA}_{j k t}^{ \pm} \\
& -\sum_{j=1}^{4} \sum_{k=1}^{9} \sum_{t=1}^{2} \mathrm{CM}_{j t}^{ \pm} \cdot \mathrm{AM}_{j k t}^{ \pm}
\end{aligned}
$$

$$
\begin{aligned}
& -\sum_{j=1}^{4} \sum_{k=1}^{9} \sum_{t=1}^{2} \mathrm{CF}_{j t}^{ \pm} \cdot \mathrm{AF}_{j k t}^{ \pm} \\
& -\sum_{i=1}^{5} \sum_{t=1}^{2} L_{t} \cdot \mathrm{PLC}_{i t}^{ \pm} \cdot \mathrm{WC}_{i t}^{ \pm} \cdot \mathrm{CC}_{i t}^{ \pm} \\
& -\sum_{s=1}^{4} \sum_{t=1}^{2} L_{t} \cdot \mathrm{QW}_{s t}^{ \pm} \cdot \mathrm{GT}_{s t}^{ \pm} \cdot \mathrm{CT}_{s t}^{ \pm} \\
& -\sum_{j=1}^{4} \sum_{k=1}^{9} \sum_{t=1}^{2} \mathrm{PA}_{j k t}^{ \pm} \cdot \mathrm{IQ}_{j k t}^{ \pm} \cdot \mathrm{WSP}_{t}^{ \pm} \\
& -\sum_{i=1}^{5} \sum_{t=1}^{2} L_{t} \cdot \mathrm{PLC}_{i t}^{ \pm} \cdot \mathrm{FW}_{i t}^{ \pm} \cdot \mathrm{WSP}_{t}^{ \pm} \\
& -\sum_{s=1}^{4} \sum_{t=1}^{2} L_{t} \cdot \mathrm{QW}_{s t}^{ \pm} \cdot \mathrm{WSP}_{t}^{ \pm}
\end{aligned}
$$

subject to

(1) wastewater treatment capacity constraints:

$$
\begin{aligned}
\mathrm{QW}_{s t}^{ \pm} \cdot \mathrm{GT}_{s t}^{ \pm} & \leq \mathrm{TPC}_{s t}^{ \pm} \\
\mathrm{WC}_{i t}^{ \pm} \cdot \mathrm{PLC}_{i t}^{ \pm} & \leq \mathrm{TPD}_{i t}^{ \pm},
\end{aligned}
$$

(2) BOD discharge constraints:

$$
\begin{aligned}
& \operatorname{Cr}\left\{\mathrm{PLC}_{i t}^{ \pm} \cdot \mathrm{WC}_{i t}^{ \pm} \cdot \mathrm{IC}_{i t}^{ \pm} \cdot\left(1-\eta_{\mathrm{BOD}, i t}^{ \pm}\right) \leq \widetilde{\mathrm{ABC}_{i t}^{ \pm}}\right\} \geq \lambda^{ \pm} \\
& \operatorname{Cr}\left\{\mathrm{QW}_{s t}^{ \pm} \cdot \mathrm{GT}_{s t}^{ \pm} \cdot \mathrm{BM}_{s t}^{ \pm} \cdot\left(1-\eta_{\mathrm{BOD}, s t}^{\prime \pm}\right) \leq \widetilde{\mathrm{ABW}_{s t}^{ \pm}}\right\} \geq \lambda^{ \pm},
\end{aligned}
$$

(3) nitrogen discharge constraints:

$$
\begin{gathered}
\mathrm{Cr}\left\{\left(L_{t} \cdot \sum_{r=1}^{4} \mathrm{AML}_{r t}^{ \pm} \cdot \mathrm{NL}_{r}^{ \pm}+L_{t}\right.\right. \\
\left.\cdot \mathrm{AMH}_{t}^{ \pm} \cdot \mathrm{RP}_{t}^{ \pm}-\sum_{j=1}^{4} \sum_{k=1}^{9} \mathrm{AM}_{j k t}^{ \pm}\right) \\
\cdot \mathrm{MS}_{t}^{ \pm} \cdot \varepsilon_{\mathrm{NM}}^{ \pm}+L_{t} \cdot \mathrm{RP}_{t}^{ \pm} \cdot \mathrm{AC}_{t}^{ \pm} \cdot \mathrm{DNR}_{t}^{ \pm} \\
\left.\leq \widetilde{\mathrm{ANL}_{t}^{ \pm}}\right\} \geq \lambda^{ \pm} \\
\sum_{k=1}^{9}\left(\mathrm{NS}_{j k}^{ \pm} \cdot \mathrm{SL}_{j k t}^{ \pm}+\mathrm{RF}_{j k t}^{ \pm} \cdot \mathrm{DN}_{j k t}^{ \pm}\right) \cdot \mathrm{PA}_{j k t}^{ \pm} \\
\leq \mathrm{MNL}_{j t}^{ \pm} \cdot \mathrm{TA}_{j t}^{ \pm},
\end{gathered}
$$


(4) phosphorus discharge constraints:

$$
\begin{gathered}
\mathrm{Cr}\left\{\mathrm { PLC } _ { i t } ^ { \pm } \cdot \left[\mathrm{WC}_{i t}^{ \pm} \cdot \mathrm{PCR}_{i t}^{ \pm} \cdot\left(1-\eta_{\mathrm{TP}, i t}^{ \pm}\right)\right.\right. \\
\left.\left.+\mathrm{ASC}_{i t}^{ \pm} \cdot \mathrm{SLR}_{i t}^{ \pm} \cdot \mathrm{PSC}_{i t}^{ \pm}\right] \leq \widetilde{\mathrm{APC}_{i t}^{ \pm}}\right\} \geq \lambda^{ \pm} \\
\operatorname{Cr}\left\{\left(L_{t} \cdot \sum_{r=1}^{4} \mathrm{AML}_{r t}^{ \pm} \cdot \mathrm{NL}_{r}^{ \pm}+L_{t} \cdot \mathrm{AMH}_{t}^{ \pm}\right.\right. \\
\left.\cdot \mathrm{RP}_{t}^{ \pm}-\sum_{j=1}^{4} \sum_{k=1}^{9} \mathrm{AM}_{j k t}^{ \pm}\right) \\
\left.\cdot \mathrm{MS}_{t}^{ \pm} \cdot \varepsilon_{P M}^{ \pm}+L_{t} \cdot \mathrm{RP}_{t}^{ \pm} \cdot \mathrm{AC} \mathrm{W}_{t}^{ \pm} \cdot \mathrm{DPR}_{t}^{ \pm} \leq \widetilde{\mathrm{APL}_{t}^{ \pm}}\right\}
\end{gathered}
$$$$
\geq \lambda^{ \pm}
$$

$$
\operatorname{Cr}\left\{\mathrm{QW}_{s t}^{ \pm} \cdot \mathrm{GT}_{s t}^{ \pm} \cdot \mathrm{PCM}_{s t}^{ \pm} \cdot\left(1-\eta_{T P, s t}^{ \pm}\right) \leq \widetilde{\mathrm{APW}_{s t}^{ \pm}}\right\} \geq \lambda^{ \pm}
$$

$$
\begin{aligned}
\operatorname{Cr}\left\{\mathrm{PLM}_{p t}^{ \pm} \cdot \mathrm{WPM}_{p t}^{ \pm} \cdot \mathrm{MWC}_{p t}^{ \pm} \cdot\left(1-\theta_{p t}^{ \pm}\right)\right. \\
\left.+\mathrm{PLM}_{p t}^{ \pm} \cdot \mathrm{ASM}_{p t}^{ \pm} \cdot \mathrm{PCS}_{p t}^{ \pm} \cdot \mathrm{SLW}_{p t}^{ \pm} \leq \widetilde{\mathrm{APM}_{p t}^{ \pm}}\right\} \geq \lambda^{ \pm}
\end{aligned}
$$

$$
\sum_{k=1}^{9}\left(\mathrm{PS}_{j k}^{ \pm} \cdot \mathrm{SL}_{j k t}^{ \pm}+\mathrm{RF}_{j k t}^{ \pm} \cdot \mathrm{DP}_{j k t}^{ \pm}\right) \cdot \mathrm{PA}_{j k t}^{ \pm} \leq \mathrm{MPL}_{j t}^{ \pm} \cdot \mathrm{TA}_{j t}^{ \pm} \text {, }
$$

(5) soil loss constraints:

$$
\sum_{k=1}^{9} \mathrm{SL}_{j k t}^{ \pm} \cdot \mathrm{PA}_{j k t}^{ \pm} \leq \mathrm{MSL}_{j t}^{ \pm} \cdot \mathrm{TA}_{j t}^{ \pm}
$$

(6) fertilizer and manure constraints:

$$
\begin{gathered}
\left(1-\mathrm{NVF}_{t}^{ \pm}\right) \cdot \varepsilon_{\mathrm{NF}}^{ \pm} \cdot \mathrm{AF}_{j k t}^{ \pm}+\left(1-\mathrm{NVM}_{t}^{ \pm}\right) \\
\cdot \varepsilon_{\mathrm{NM}}^{ \pm} \cdot \mathrm{AM}_{j k t}^{ \pm}-\mathrm{NR}_{j k t}^{ \pm} \cdot \mathrm{PA}_{j k t}^{ \pm} \geq 0 \\
\varepsilon_{\mathrm{PF}}^{ \pm} \cdot \mathrm{AF}_{j k t}^{ \pm}+\varepsilon_{\mathrm{PM}}^{ \pm} \cdot \mathrm{AM}_{j k t}^{ \pm}-\mathrm{PR}_{j k t}^{ \pm} \cdot \mathrm{PA}_{j k t}^{ \pm} \geq 0, \\
\sum_{k=1}^{9}\left(\varepsilon_{\mathrm{NF}}^{ \pm} \cdot \mathrm{AF}_{j k t}^{ \pm}+\varepsilon_{\mathrm{NM}}^{ \pm} \cdot \mathrm{AM}_{j k t}^{ \pm}-\mathrm{NR}_{j k t}^{ \pm} \cdot \mathrm{PA}_{j k t}^{ \pm}\right) \\
\leq \mathrm{MNL}_{j t}^{ \pm} \cdot \mathrm{TA}_{j t}^{ \pm},
\end{gathered}
$$

$$
\begin{aligned}
& \sum_{k=1}^{9}\left(\varepsilon_{\mathrm{PF}}^{ \pm} \cdot \mathrm{AF}_{j k t}^{ \pm}+\varepsilon_{P M}^{ \pm} \cdot \mathrm{AM}_{j k t}^{ \pm}-\mathrm{PR}_{j k t}^{ \pm} \cdot \mathrm{PA}_{j k t}^{ \pm}\right) \\
& \leq \mathrm{MPL}_{j t}^{ \pm} \cdot \mathrm{TA}_{j t}^{ \pm},
\end{aligned}
$$

$$
L_{t} \cdot \sum_{r=1}^{4} \mathrm{AML}_{r t}^{ \pm} \cdot \mathrm{NL}_{r}^{ \pm}+L_{t} \cdot \mathrm{AMH}_{t}^{ \pm} \cdot \mathrm{RP}_{t}^{ \pm}-\sum_{j=1}^{4} \sum_{k=1}^{9} \mathrm{AM}_{j k t}^{ \pm} \geq 0,
$$

(7) energy and digestible protein constraints:

$$
\begin{aligned}
\sum_{j=1}^{4} \sum_{k=1}^{9} \sum_{t=1}^{2} \mathrm{CY}_{j k t}^{ \pm} \cdot \mathrm{PA}_{j k t}^{ \pm} \cdot \mathrm{NEC}_{k}^{ \pm}-\sum_{r=1}^{4} \mathrm{ERL}_{r}^{ \pm} \cdot \mathrm{NL}_{r}^{ \pm} \\
-\sum_{t=1}^{2} \mathrm{ERH}_{t}^{ \pm} \cdot \mathrm{RP}_{t}^{ \pm} \geq 0,
\end{aligned}
$$

$$
\begin{aligned}
\sum_{j=1}^{4} \sum_{k=1}^{9} & \sum_{t=1}^{2} \mathrm{CY}_{j k t}^{ \pm} \cdot \mathrm{PA}_{j k t}^{ \pm} \cdot \mathrm{DPC}_{k}^{ \pm} \\
& -\sum_{r=1}^{4} \mathrm{DRL}_{r}^{ \pm} \cdot \mathrm{NL}_{r}^{ \pm}-\sum_{t=1}^{2} \mathrm{DRH}_{t}^{ \pm} \cdot \mathrm{RP}_{t}^{ \pm} \geq 0
\end{aligned}
$$

(8) production scale constraints:

$$
\begin{gathered}
\mathrm{PLC}_{i, \text { min }} \leq \mathrm{PLC}_{i t}^{ \pm} \leq \mathrm{PLC}_{i, \text { max }}, \\
\mathrm{NL}_{r, \text { min }} \leq \mathrm{NL}_{r}^{ \pm} \leq \mathrm{NL}_{r, \text { max }}, \\
\mathrm{QW}_{s, \text { min }} \leq \mathrm{QW}_{s t}^{ \pm} \leq \mathrm{QW}_{s, \text { max }}, \\
\mathrm{PLM}_{p, \text { min }} \leq \mathrm{PLM}_{p t}^{ \pm} \leq \mathrm{PLM}_{p, \text { max }},
\end{gathered}
$$

(9) total yield of crops:

$$
\sum_{j=1}^{4} \mathrm{CY}_{j k t}^{ \pm} \cdot \mathrm{PA}_{j k t}^{ \pm} \geq \mathrm{MCY}_{k t}^{ \pm}
$$

(10) planning area constraints:

$$
\sum_{k=1}^{9} \mathrm{PA}_{j k t}^{ \pm} \leq \mathrm{TA}_{j t}^{ \pm}
$$

(11) nonnegative constraints:

$$
\mathrm{PLC}_{i t}^{ \pm}, \mathrm{PA}_{j k t}^{ \pm}, \mathrm{NL}_{r}^{ \pm}, \mathrm{QW}_{s t}^{ \pm}, \mathrm{PLM}_{p t}^{ \pm}, \mathrm{AM}_{j k t}^{ \pm}, \mathrm{AF}_{j k t}^{ \pm} \geq 0,
$$

where $i$ : chemical plant; $i=1 \mathrm{Gufu}(\mathrm{GF}) ; i=2$ Baishahe (BSH); $i=3$ Pingyikou (PYK); $i=4$ Liucaopo (LCP); $i=5$ Xiangjinlianying (XJLY); $j$ : agricultural zone; $j=1, \ldots, 4$; $k$ : main crop; $k=1$ citrus; $k=2$ tea; $k=3$ wheat; $k=4$ potato; $k=5$ rapeseed; $k=6$ alpine rice; $k=7$ second rice; $k=8$ maize; $k=9$ vegetables; $p$ : phosphorus mining company; $p=1$ Xinglong (XL); $p=2$ Xinghe $(\mathrm{XH}) ; p=3$ 
TABLE 1: Net benefits from each production.

\begin{tabular}{|c|c|c|}
\hline & \multicolumn{2}{|c|}{ Period } \\
\hline & $t=1$ & $t=2$ \\
\hline \multicolumn{3}{|c|}{ Net benefits from chemical plant (RMB¥/t) } \\
\hline GF & {$[718.6,834.5]$} & {$[743.75,876.2]$} \\
\hline $\mathrm{BSH}$ & {$[1291.5,1499.7]$} & {$[1336.7,1574.8]$} \\
\hline PYK & {$[743.0,862.8]$} & {$[769.0,905.9]$} \\
\hline LCP & {$[1324.2,1537.5]$} & {$[1370.6,1614.4]$} \\
\hline XJLY & {$[1524.4,1770.0]$} & {$[1578.7,1858.5]$} \\
\hline \multicolumn{3}{|c|}{ Net benefits from water supply $\left(\mathrm{RMB} ¥ / \mathrm{m}^{3}\right)$} \\
\hline Gufu & {$[39.1,42.1]$} & {$[43.4,47.7]$} \\
\hline Nanyang & {$[29.0,31.2]$} & {$[32.2,35.4]$} \\
\hline Gaoyang & {$[35.3,38.0]$} & {$[39.2,43.1]$} \\
\hline Xiakou & {$[32.1,34.6]$} & {$[35.7,39.3]$} \\
\hline \multicolumn{3}{|c|}{ Net benefits from phosphorus mining company (RMB¥/t) } \\
\hline XL (Xinglong, $p=1$ ) & {$[150,173]$} & {$[147,180]$} \\
\hline XH (Xinghe, $p=2$ ) & {$[126,145]$} & {$[130,156]$} \\
\hline XC (Xingchang, $p=3$ ) & {$[135,155]$} & {$[135,162]$} \\
\hline GP (Geping, $p=4$ ) & {$[144,166]$} & {$[150,180]$} \\
\hline JJW (Jiangjiawan, $p=5$ ) & {$[137,158]$} & {$[141,169]$} \\
\hline SJS (Shenjiashan, $p=6$ ) & {$[140,164]$} & {$[145,175]$} \\
\hline
\end{tabular}

Xingchang (XC); $p=4$ Geping (GP); $p=5$ Jiangjiawan (JJW); $p=6$ Shenjiashan (SJS); $r$ : livestock; $r=1$ pig; $r=2$ ox; $r=3$ sheep; $r=4$ domestic fowls; $s$ : town; $s=1 \mathrm{Gufu} ; s=2$ Nanyang; $s=3$ Gaoyang; $s=4$ Xiakou; $t$ : time period; $t=1$ dry season; $t=2$ wet season; $L_{t}$ : length of period (day); $\mathrm{BC}_{i t}^{ \pm}$: net benefit from chemical plant $i$ during period $t(\mathrm{RMB} / \mathrm{t}) ; \mathrm{PLC}_{i t}^{ \pm}$: production level of chemical plant $i$ during period $t$ (t/day); $\mathrm{BW}_{s t}^{ \pm}$: benefit from water supply to municipal uses $\left(\mathrm{RMB} ¥ / \mathrm{m}^{3}\right) ; \mathrm{QW}_{s t}^{ \pm}$: quantity of water supply to town $s$ in period $t\left(\mathrm{~m}^{3} /\right.$ day); $\mathrm{BP}_{p t}^{ \pm}$: average benefit for per unit phosphate ore (RMB¥/t); $\mathrm{PLM}_{p t}^{ \pm}$: production level of phosphorus mining company $p$ during period $t$ (t/day); $\mathrm{BL}_{r}^{ \pm}$: average benefit from livestock $r$ (RMB¥/unit); $\mathrm{NL}_{r}^{ \pm}$: number of livestock $r$ in the study area (unit); $\mathrm{CY}_{j k t}^{ \pm}$: yield of crop $k$ planted in agricultural zone $j$ during period $t$ (t/ha); $\mathrm{BA}_{j k t}^{ \pm}$: average benefit of agricultural product $(\mathrm{RMB} ¥ \mathrm{t}) ; \mathrm{PA}_{j k t}^{ \pm}$: planting area of crop $k$ in agricultural zone $j$ during period $t$ (ha); $\mathrm{CM}_{j t}^{ \pm}$: cost of manure collection/disposal in agricultural zone $j$ during period $t(\mathrm{RMB} ¥ \mathrm{t}) ; \mathrm{CF}_{j t}^{ \pm}$: cost of purchasing fertilizer in agricultural zone $j$ during period $t(\mathrm{RMB} ¥ / \mathrm{t}) ; \mathrm{AM}_{j k t}^{ \pm}$: amount of manure applied to agricultural zone $j$ with crop $k$ during period $t(\mathrm{t}) ; \mathrm{AF}_{j k t}^{ \pm}$: amount of fertilizer applied to agricultural zone $j$ with crop $k$ during period $t(\mathrm{t})$; $\mathrm{WC}_{i t}^{ \pm}$: wastewater generation rate of chemical plant $i$ during period $t\left(\mathrm{~m}^{3} / \mathrm{t}\right)$; $\mathrm{CC}_{i t}^{ \pm}$: wastewater treatment cost of chemical plant $i$ during period $t\left(\mathrm{RMB} ¥ / \mathrm{m}^{3}\right) ; \mathrm{GT}_{s t}^{ \pm}$: wastewater discharge amount at town $s$ during period $t\left(\mathrm{~m}^{3} / \mathrm{m}^{3}\right)$; $\mathrm{CT}_{s t}^{ \pm}$: cost of municipal wastewater treatment $\left(\mathrm{RMB} / \mathrm{m}^{3}\right) ; \mathrm{IQ}_{j k t}^{ \pm}$: irrigation quota for crop $k$ in zone $j$ during period $t\left(\mathrm{~m}^{3} / \mathrm{ha}\right)$; $\mathrm{WSP}_{t}^{ \pm}$: water supply price $\left(\mathrm{RMB} ¥ / \mathrm{m}^{3}\right)$; $\mathrm{FW}_{i t}^{ \pm}$: water consumption of per unit production of chemical plant $i$ during period $t\left(\mathrm{~m}^{3} / \mathrm{t}\right)$; $\mathrm{IC}_{i t}^{ \pm}$: BOD concentration of raw wastewater from chemical plant $i$ in period $t\left(\mathrm{~kg} / \mathrm{m}^{3}\right) ; \eta_{\mathrm{BOD}, i t}^{ \pm}$: BOD treatment efficiency in chemical plant $i$ during period $t(\%) ; \widetilde{\mathrm{ABC}_{i t}^{ \pm}}$: allowable BOD discharge for chemical plant $i$ in period $t$ (kg/day); $\mathrm{BM}_{s t}^{ \pm}$: BOD concentration of municipal wastewater at town $s$ during period $t\left(\mathrm{~kg} / \mathrm{m}^{3}\right) ; \eta_{\mathrm{BOD}, s t}^{\prime \pm}$ : BOD treatment efficiency of WTPs at town $s$ during period $t(\%) ; \widetilde{\mathrm{ABW}_{s t}^{ \pm}}$: allowable BOD discharge for WTPs at town $s$ during period $t$ (kg/day); $\mathrm{NS}_{j k}^{ \pm}$: nitrogen content of soil in agricultural zone $j$ planted with crop $k(\%) ; \mathrm{SL}_{j k t}^{ \pm}$: average soil loss from agricultural zone $j$ planted with crop $k$ in period $t(\mathrm{t} / \mathrm{ha}) ; \mathrm{RF}_{j k t}^{ \pm}$: runoff from agricultural zone $j$ with crop $k$ in period $t(\mathrm{~mm})$; $\mathrm{DN}_{j k t}^{ \pm}$: dissolved nitrogen concentration in the runoff from agricultural zone $j$ planted with crop $k$ in period $t(\mathrm{mg} / \mathrm{L})$; $\mathrm{MNL}_{j t}^{ \pm}$: maximum allowable nitrogen loss in agricultural zone $j$ during period $t(\mathrm{t} / \mathrm{ha}) ; \mathrm{TA}_{j t}^{ \pm}$: tillable area of agricultural zone $j$ during period $t(\mathrm{ha}) ; \mathrm{AML}_{r t}^{ \pm}$: amount of manure generated by livestock $r$ [t/(unit.day $\left.\left.{ }^{-1}\right)\right] ; \mathrm{AMH}_{t}^{ \pm}$: amount of manure generated by humans $\left[\mathrm{t} /\left(\right.\right.$ unit $\left.\left.^{-d_{a y}}{ }^{-1}\right)\right] ; \mathrm{RP}_{t}^{ \pm}$: total rural population in the study area during period $t$ (unit); $\mathrm{MS}_{t}^{ \pm}$: manure loss rate in period $t(\%) ; \mathrm{AC} \mathrm{W}_{t}^{ \pm}$: wastewater generation of per capita water consumption during period $t$ $\left[\mathrm{m}^{3} /\left(\right.\right.$ unit.day $\left.\left.^{-1}\right)\right] ; \mathrm{DNR}_{0 t}^{ \pm}$: dissolved nitrogen concentration of rural wastewater during period $t\left(\mathrm{t} / \mathrm{m}^{3}\right) ; \widetilde{\mathrm{ANL}_{t}^{ \pm}}$: maximum allowable nitrogen loss from rural life section in period $t(\mathrm{t}) ; \mathrm{PCR}_{i t}^{ \pm}$: phosphorus concentration of raw wastewater from chemical plant $i$ in period $t\left(\mathrm{~kg} / \mathrm{m}^{3}\right) ; \eta_{\mathrm{TP}, i t}^{ \pm}$: phosphorus treatment efficiency in chemical plant $i$ in period $t(\%) ; \mathrm{ASC}_{i t}^{ \pm}$: amount of slag discharged by chemical plant $i$ in period $t$ $(\mathrm{kg} / \mathrm{t}) ; \mathrm{SLR}_{i t}^{ \pm}$: slag loss rate due to rain wash in chemical plant $i$ during period $t(\%)$; PSC $_{i t}^{ \pm}$: phosphorus content in slag generated by chemical plant $i$ in period $t(\%) ; \widetilde{\mathrm{APC}_{i t}^{ \pm}}$: allowable phosphorus discharge for chemical plant $i$ in period $t$ (kg/day); $\mathrm{PS}_{j k}^{ \pm}$: phosphorus content of soil in agricultural zone $j$ planted with crop $k(\%) ; \mathrm{SL}_{j k t}^{ \pm}$: average soil loss from agricultural zone $j$ planted with crop $k$ in period $t$ (t/ha); $\mathrm{RF}_{j k t}^{ \pm}$: runoff from agricultural zone $j$ with crop $k$ in period $t(\mathrm{~mm}) ; \mathrm{DP}_{j k t}^{ \pm}$: dissolved phosphorus concentration in the runoff from agricultural zone $j$ planted with crop $k$ in period $t(\mathrm{mg} / \mathrm{L})$; $\mathrm{MPL}_{j t}^{ \pm}$: maximum allowable phosphorus loss in agricultural zone $j$ during period $t$ (t/ha); $\mathrm{DPR}_{t}^{ \pm}$: dissolved phosphorus concentration of rural wastewater during period $t\left(\mathrm{t} / \mathrm{m}^{3}\right) ; \widetilde{\mathrm{APL}_{t}^{ \pm}}$: maximum allowable phosphorus loss from rural life during period $t(\mathrm{t}) ; \mathrm{PCM}_{s t}^{ \pm}$: phosphorus concentration of municipal wastewater at town $s$ in period $t\left(\mathrm{~kg} / \mathrm{m}^{3}\right) ; \eta_{\mathrm{TP}, s t}^{ \pm}$: phosphorus treatment efficiency of WTP at town $s$ in period $t(\%) ; \widetilde{\mathrm{APW}_{s t}^{ \pm}}$: allowable phosphorus discharge for WTP at town $s$ in period $t\left(\mathrm{~kg} /\right.$ day); $\mathrm{WPM}_{p t}^{ \pm}$: wastewater generation from phosphorus mining company $p$ in period $t\left(\mathrm{~m}^{3} / \mathrm{t}\right) ; \mathrm{MWC}_{\mathrm{p} t}^{ \pm}$: phosphorus concentration of wastewater from mining company $p$ in period $t\left(\mathrm{~kg} / \mathrm{m}^{3}\right)$; $\theta_{p t}^{ \pm}$: phosphorus treatment efficiency in mining company $p$ 
TABLE 2: Crop yields and net benefits.

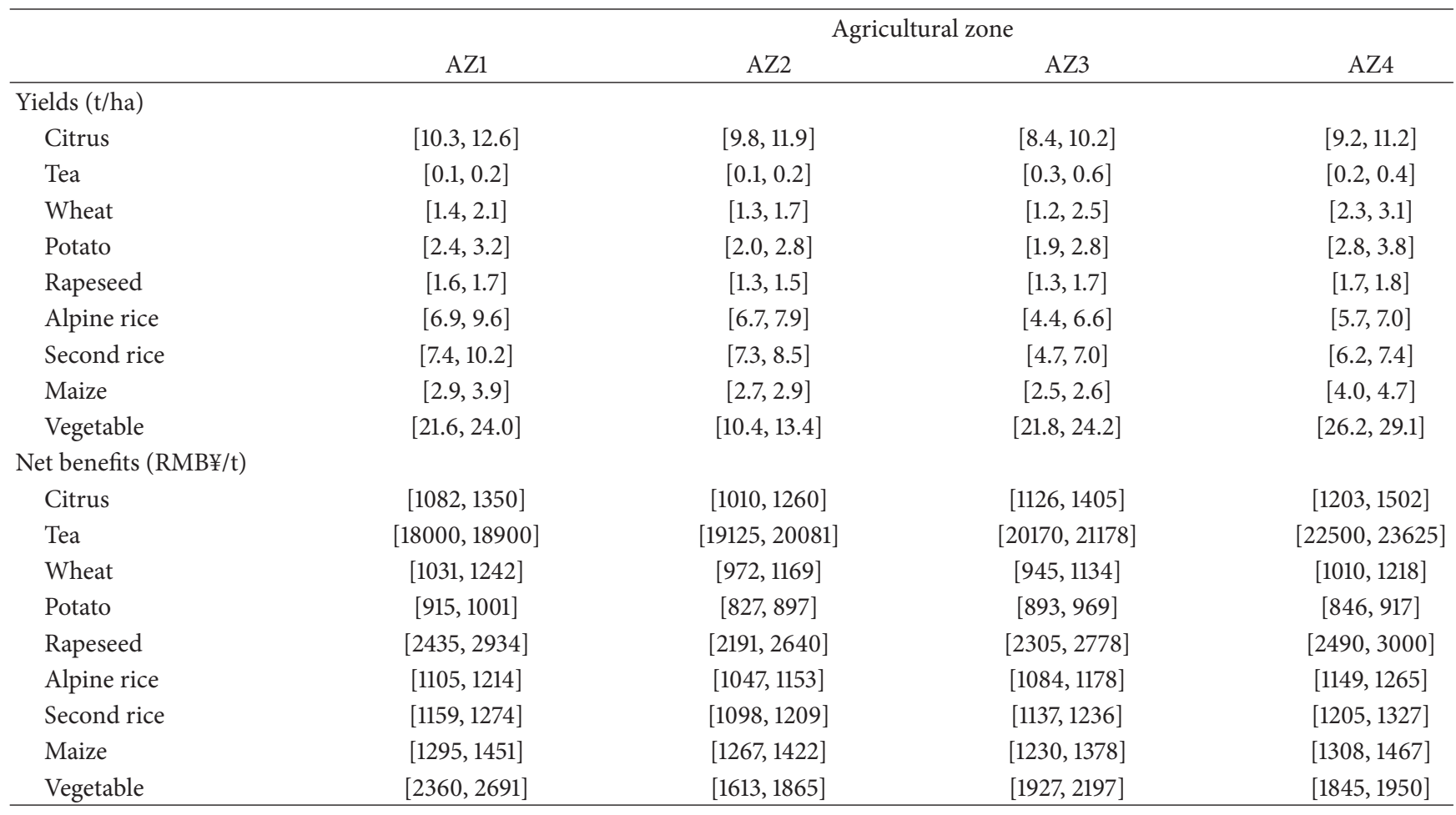

(\%); $\operatorname{ASM}_{p t}^{ \pm}$: amount of slag discharged by mining company $p$ during period $t(\mathrm{~kg} / \mathrm{t}) ; \mathrm{PCS}_{p t}^{ \pm}$: phosphorus content in generated slag (\%); $\mathrm{SLW}_{p t}^{ \pm}$: slag loss rate due to rain wash (\%); $\widetilde{\mathrm{APM}_{p t}^{ \pm}}:$allowable phosphorus discharge for mining company $p$ during period $t$ (kg/day); $\mathrm{MSL}_{j t}^{ \pm}$: maximum allowable soil loss agricultural zone $j$ in period $t(\mathrm{t} / \mathrm{ha}) ; \mathrm{NVF}_{t}^{ \pm}$: nitrogen volatilization/denitrification rate of fertilizer in period $t(\%)$; $\mathrm{NVM}_{t}^{ \pm}$: nitrogen volatilization/denitrification rate of manure in period $t(\%) ; \varepsilon_{\mathrm{NF}}^{ \pm}$: nitrogen content of fertilizer $(\%) ; \varepsilon_{\mathrm{PF}}^{ \pm}$: phosphorus content of fertilizer (\%); $\varepsilon_{\mathrm{NM}}^{ \pm}$: nitrogen content of manure $(\%) ; \varepsilon_{\mathrm{PM}}^{ \pm}$: phosphorus content of manure (\%); $\mathrm{NR}_{j k t}^{ \pm}$: nitrogen requirement of agricultural zone $j$ with crop $k$ during period $t$ (t/ha); $\mathrm{PR}_{j k t}^{ \pm}$: phosphorus requirement of crop $k$ in agricultural zone $j$ during period $t(\mathrm{t} / \mathrm{ha}) ; \mathrm{NEC}_{k}^{ \pm}$: net energy content of crop $k(\mathrm{Mcal} / \mathrm{t}) ; \mathrm{ERL}_{r}^{ \pm}$: net energy requirement of livestock $r$ (Mcal/unit); $\mathrm{ERH}_{t}^{ \pm}$: net energy requirement of human beings ( $\mathrm{Mcal} /$ unit); $\mathrm{DPC}_{k}^{ \pm}$: digestible protein content of crop $k(\%)$; $\mathrm{DRL}_{r}^{ \pm}$: digestible protein requirement of livestock $r$ (t/unit); $\mathrm{DRH}_{t}^{ \pm}$: digestible protein requirement of human beings (t/unit); $\mathrm{MCY}_{j k t}^{ \pm}$: minimum crop production requirement for crop $k$ in period $t(\mathrm{t}) ; \mathrm{TPC}_{s t}^{ \pm}$: capacity of wastewater treatment capacity (WTPs) $\left(\mathrm{m}^{3} /\right.$ day); $\mathrm{TPD}_{i t}^{ \pm}$: capacity of wastewater treatment capacity (chemical plants) ( $\mathrm{m}^{3} /$ day).

Table 1 provides the net benefits of chemical plant productions, phosphorus mining company, and municipal water supply. According to the crops' growth periods, dry season crops include wheat, potato, rapeseed and alpine rice; second rice, maize and vegetable are identified as main crops during the wet season; citrus and tea grow over the entire year. Table 2 shows the net benefits of each crop in every AZ and yields of each crop. To guarantee the stream water quality, wastewater treatment measures have to be adopted at each point source. Based on the local environmental regulations, a safe level of water quality must be guaranteed to protect aquatic life and maintain aerobic condition in the stream system [2]. Thus, the BOD and TP loading amount would be controlled strictly. However, the imprecision of the allowable BOD and TP discharge could introduce uncertainties in the water quality management. For modeling purpose, the vagueness of the allowable BOD and TP loading amount are encoded by triangular fuzzy membership functions. Figure 1 presents the fuzzy set with triangular membership function. The minimum, maximum, and most likely values $(\underline{b}, b$, and $\bar{b})$ that define these fuzzy sets are estimated according to previous research regarding water quality monitoring and environmental capacities, as tabulated in Table 3. Moreover, by setting acceptable interval credibility levels, the constraints can be at least basically satisfied and at best practically satisfied. Lower-bound of the interval numbers would be no less than 0.5 , and upper- bound of the interval numbers would be no more than 1 [16]. Lower-bound of credibility level represents a situation when the decision makers are optimistic about this study area, which may imply a higher risk of violating the river's self-purification capacity. Conversely, upper-bound of credibility level corresponds to a situation when the decision makers prefer a conservative policy that could guarantee that the river's self-purification capacity be satisfied. 
TABLE 3: Allowable BOD and TP discharges.

\begin{tabular}{|c|c|c|c|c|c|c|}
\hline & \multicolumn{2}{|c|}{$\underline{b}$} & \multicolumn{2}{|c|}{$b$} & \multicolumn{2}{|c|}{$\bar{b}$} \\
\hline & $t=1$ & $t=2$ & $t=1$ & $t=2$ & $t=1$ & $t=2$ \\
\hline & \multicolumn{6}{|c|}{$\begin{array}{l}\text { Allowable BOD loading discharge } \\
\text { from chemical plant (kg/day) }\end{array}$} \\
\hline GF & 0.76 & 0.78 & 0.82 & 0.85 & 0.88 & 0.92 \\
\hline BSH & 437.2 & 442.97 & 444.265 & 448.605 & 451.33 & 454.24 \\
\hline PYK & 7.25 & 7.83 & 7.53 & 7.89 & 7.81 & 7.95 \\
\hline LCP & 95.43 & 97.23 & 97.82 & 102.83 & 100.21 & 108.43 \\
\hline \multirow[t]{2}{*}{ XJLY } & 48.34 & 49.43 & 49.635 & 50.645 & 50.93 & 51.86 \\
\hline & \multicolumn{6}{|c|}{$\begin{array}{l}\text { Allowable BOD loading discharge } \\
\text { from WTP (kg/day) }\end{array}$} \\
\hline Gufu & 145 & 143 & 150 & 148 & 155 & 153 \\
\hline Nanyang & 7 & 6 & 10 & 9 & 13 & 12 \\
\hline Gaoyang & 38 & 36 & 40 & 38 & 42 & 40 \\
\hline Xiakou & 28 & 30 & 30 & 32 & 32 & 34 \\
\hline \multicolumn{7}{|c|}{$\begin{array}{l}\text { Allowable TP loading discharge } \\
\text { from chemical plant (kg/day) }\end{array}$} \\
\hline GF & 1.18 & 1.29 & 1.31 & 1.43 & 1.44 & 1.57 \\
\hline BSH & 393.73 & 485.94 & 419.14 & 514.27 & 444.55 & 542.59 \\
\hline PYK & 80.23 & 99.57 & 84.87 & 105.75 & 89.51 & 111.92 \\
\hline LCP & 385.59 & 470.16 & 416.21 & 497.96 & 446.83 & 525.76 \\
\hline XJLY & 259.81 & 330.52 & 276.46 & 355.02 & 293.1 & 379.52 \\
\hline \multicolumn{7}{|c|}{$\begin{array}{l}\text { Allowable TP loading discharge } \\
\text { from WTP (kg/day) }\end{array}$} \\
\hline Gufu & 13.00 & 13.50 & 15.22 & 15.68 & 17.43 & 17.85 \\
\hline Nanyang & 0.36 & 0.42 & 0.55 & 0.6 & 0.74 & 0.78 \\
\hline Gaoyang & 1.82 & 1.88 & 2.03 & 2.27 & 2.23 & 2.65 \\
\hline Xiakou & 2.05 & 2.34 & 2.25 & 2.49 & 2.45 & 2.64 \\
\hline \multicolumn{7}{|c|}{$\begin{array}{l}\text { Allowable TP loading discharge } \\
\text { from phosphorus mining company }(\mathrm{kg} / \mathrm{day})\end{array}$} \\
\hline $\mathrm{XL}$ & 157.70 & 143.31 & 175.60 & 192.45 & 193.49 & 241.59 \\
\hline $\mathrm{XH}$ & 89.40 & 104.19 & 99.51 & 120.53 & 109.62 & 136.87 \\
\hline $\mathrm{XC}$ & 108.20 & 110.74 & 120.48 & 138.25 & 132.75 & 165.76 \\
\hline GP & 146.20 & 140.03 & 162.78 & 181.99 & 179.36 & 223.95 \\
\hline JJW & 89.80 & 104.49 & 99.97 & 121.01 & 110.13 & 137.52 \\
\hline SJS & 86.60 & 102.19 & 96.41 & 117.40 & 106.21 & 132.61 \\
\hline \multicolumn{7}{|c|}{$\begin{array}{l}\text { Allowable TP and TN loading discharge } \\
\text { from rural life (kg/day) }\end{array}$} \\
\hline $\mathrm{TP}$ & 21.5 & 20.5 & 24.45 & 24.4 & 27.4 & 28.3 \\
\hline $\mathrm{TN}$ & 102.1 & 106.0 & 107.5 & 107.0 & 112.8 & 118.0 \\
\hline
\end{tabular}

\section{Result Analysis}

Table 4 shows the solutions for industrial production and water supply during the two periods. The results show that significant variations in industrial production and water supply exist among different chemical plants, phosphorus mining companies, and towns. For chemical plants, the production scale of BSH (i.e., [536.23, 652.37] t/d (tonne/day) during period 1 and [530.78,629.19] t/d during period 2) would be larger than the other chemical plants (especially
TABLE 4: Solutions for industrial productions and water supplies.

\begin{tabular}{lcc}
\hline \multirow{3}{*}{ Main point sources } & \multicolumn{2}{c}{ Period } \\
& Chemical plant (t/day) & $t=2$ \\
GF & {$[25.64,27.41]$} & {$[21.13,27.02]$} \\
BSH & {$[536.23,652.37]$} & {$[530.78,629.19]$} \\
PYK & {$[81.71,102.09]$} & {$[75.98,80.92]$} \\
LCP & {$[379.24,403.72]$} & {$[357.33,453.48]$} \\
XJLY & {$[280.87,313.47]$} & {$[320.42,337.81]$} \\
\hline \multicolumn{3}{c}{ Phosphorus mining company $(\mathrm{t} / \mathrm{day})$} \\
XL & {$[824.78,1261.00]$} & {$[701.05,1044.89]$} \\
XH & {$[326.00,420.00]$} & {$[350.48,400.00]$} \\
XC & {$[286.87,400.00]$} & {$[260.38,393.68]$} \\
GP & {$[534.99,778.00]$} & {$[659.80,778.00]$} \\
JWW & {$[425.99,547.00]$} & {$[412.57,547.00]$} \\
SJS & {$[510.53,685.00]$} & {$[602.43,685.00]$} \\
\hline & Water supply $\left(\mathrm{m}^{3} /\right.$ day) & \\
Gufu & {$[11723.79,14859.14]$} & {$[12264.89,21739.14]$} \\
Nanyang & {$[762.29,987.64]$} & {$[859.73,1109.84]$} \\
Gaoyang & {$[2783.46,3225.87]$} & {$[2962.32,3226.25]$} \\
Xiakou & {$[1656.71,2083.18]$} & {$[1592.84,2156.09]$} \\
\hline
\end{tabular}

GF) because of its higher allowable BOD and TP discharges and net benefits. For water supply, more water would be delivered to Gufu (i.e., [11723.79, 14859.14] $\mathrm{m}^{3} /$ day in period 1 and $[12264.89,21739.14] \mathrm{m}^{3} /$ day in period 2) than those to the other towns due to its greater water demand, higher allowable BOD discharge, and higher economic return. For phosphorus mining company, the production scale of XL (i.e., $[824.78,1261.00] \mathrm{t} / \mathrm{d}$ in period 1 and $[701.05,1044.89] \mathrm{t} / \mathrm{d}$ in period 2) would be larger than the other chemical plants because of its higher allowable TP discharge and net benefit.

The results for total crop areas and manure/fertilizer applications are listed in Table 5. The areas of citrus and tea would maintain the low levels over the planning horizon. This may be attributed to their pollutant losses as well as their low net energy and digestible protein contents (supplied for livestock). In period 1, wheat, potato, rapeseed, and alpine rice should be cultivated. The potato area (i.e., $[1459.8,1620.3]$ ha) would account for the largest one of the entire croplands. In period 2, wheat, potato, rapeseed, and alpine rice would be harvested and second rice, maize, and vegetable would be sown. The vegetable area (i.e., [1745.2, 1915.6] ha) would be the largest one among all croplands. The results indicate that the high levels of area planted with potato and vegetable are associated with their high crop yields, good market price, and low pollutant losses. In terms of manure and fertilizer application, their quantities would vary with crop areas. The results indicate that manure would be the main nitrogen and phosphorus source which satisfy the requirements of most crops due to its availability and low price to collect. Solutions demonstrate that domestic fowl husbandry would reach the highest level 

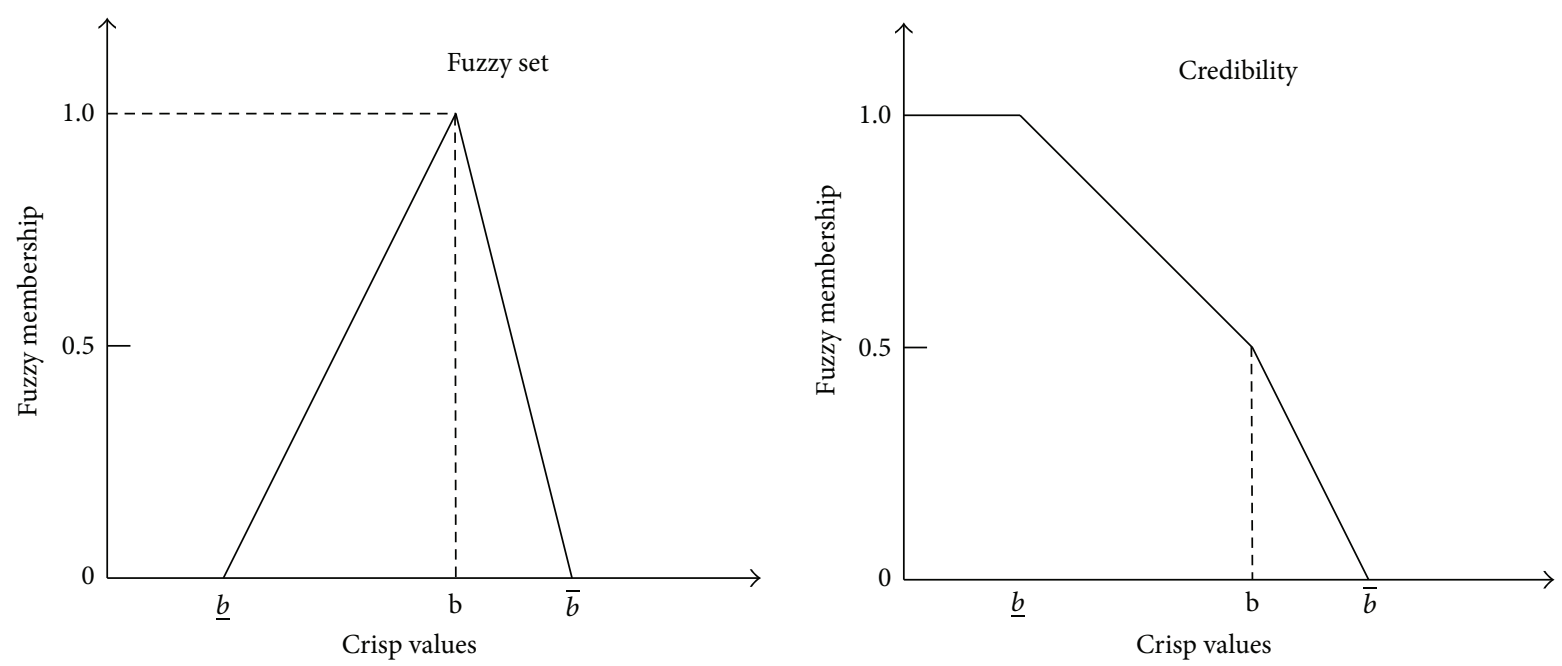

FIgURE 1: Fuzzy set and credibility.

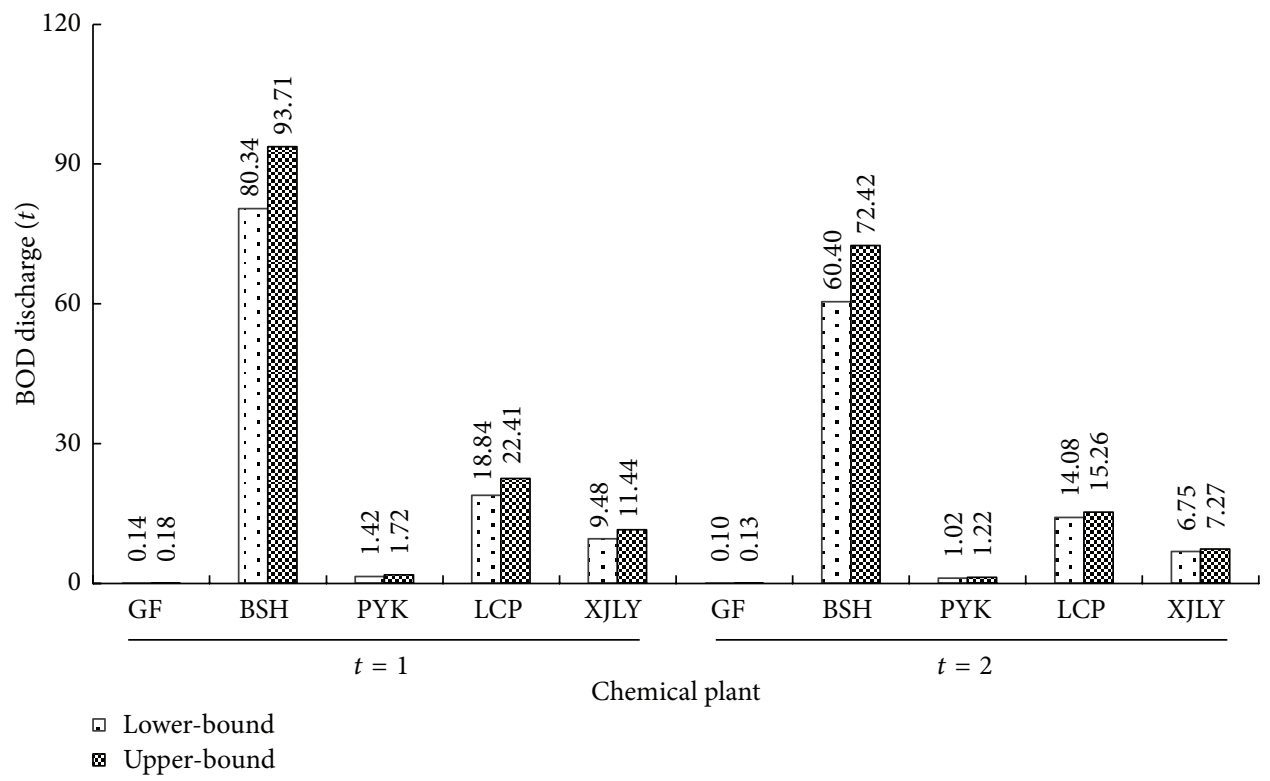

FIGURE 2: BOD discharges from chemical plants. Note: the five chemical plants are abbreviated as their initials in this figure. GF: Gufu, $i=1$; BSH: Baishahe, $i=2$; PYK: Pingyikou, $i=3$; LCP: Liucaopo, $i=4$; XJLY: Xiangjinlianying, $i=5$.

(i.e., $[34.80,132.56] \times 10^{3}$ unit) among all live stocks because it possesses more advantageous conditions than the other live stocks (i.e., higher allowable discharge, higher revenue parameter, and lower manure generation rate).

Figures 2 and 3 present the amounts of BOD discharges from chemical plants and WTPs, respectively. The amount of BOD discharge is associated with a number of factors (e.g., production scale, wastewater generation rate, and wastewater treatment facility). The BOD discharge from BSH would be more than those from the other chemical plants, which would be $[80.34,93.71] \mathrm{t}$ (i.e., tonne) in period 1 and $[60.40,72.42] \mathrm{t}$ in period 2. The BOD discharge from GF would be the lowest among all chemical plants, with $[0.14,0.18] \mathrm{t}$ in period 1 and $[0.10,0.13] \mathrm{t}$ in period 2. Among all WTPs, Gufu wastewater treatment plant would discharge the highest BOD level, with $[17.62,28.69] \mathrm{t}$ in period 1 and $[26.72,36.72] \mathrm{t}$ in period 2 ; the BOD discharged from Nanyang WTP would be the lowest (i.e. $[3.99,4.39] \mathrm{t}$ in period 1 and $[5.01,7.55] \mathrm{t}$ in period 2 ).

Figure 4 shows TP discharges from point sources (i.e., chemical plants, WTPs, and phosphorus mining companies) and nonpoint sources (i.e., crop farming and agricultural life). In Figure 4, symbol "CP" denotes chemical plant; symbol "PMC" denotes phosphorus mining company; symbol "CF" denotes crop farming; symbol "AL" means agricultural life. For point sources, the chemical plants would be the major contributor to water pollution. The phosphorus pollutants can be discharged from wastewater and solid wastes (i.e., chemical wastes, slags, and tailings). The amount of TP 


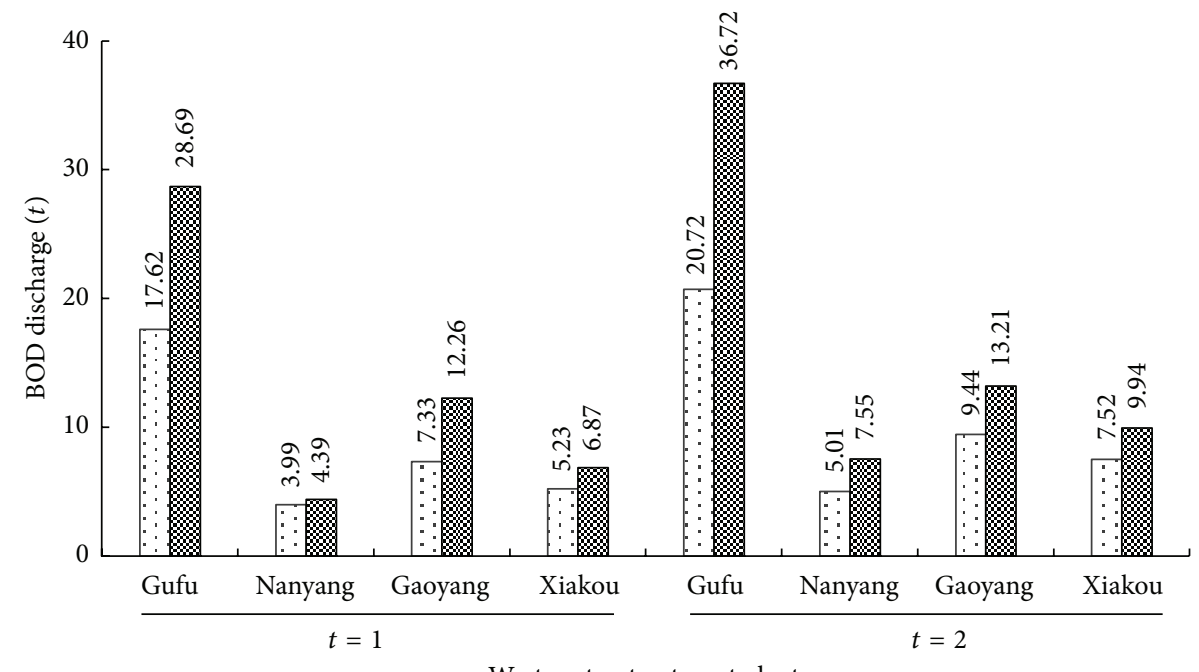

$\boxminus$ Lower-bound

圆 Upper-bound

FIGURE 3: BOD discharges from WTPs.

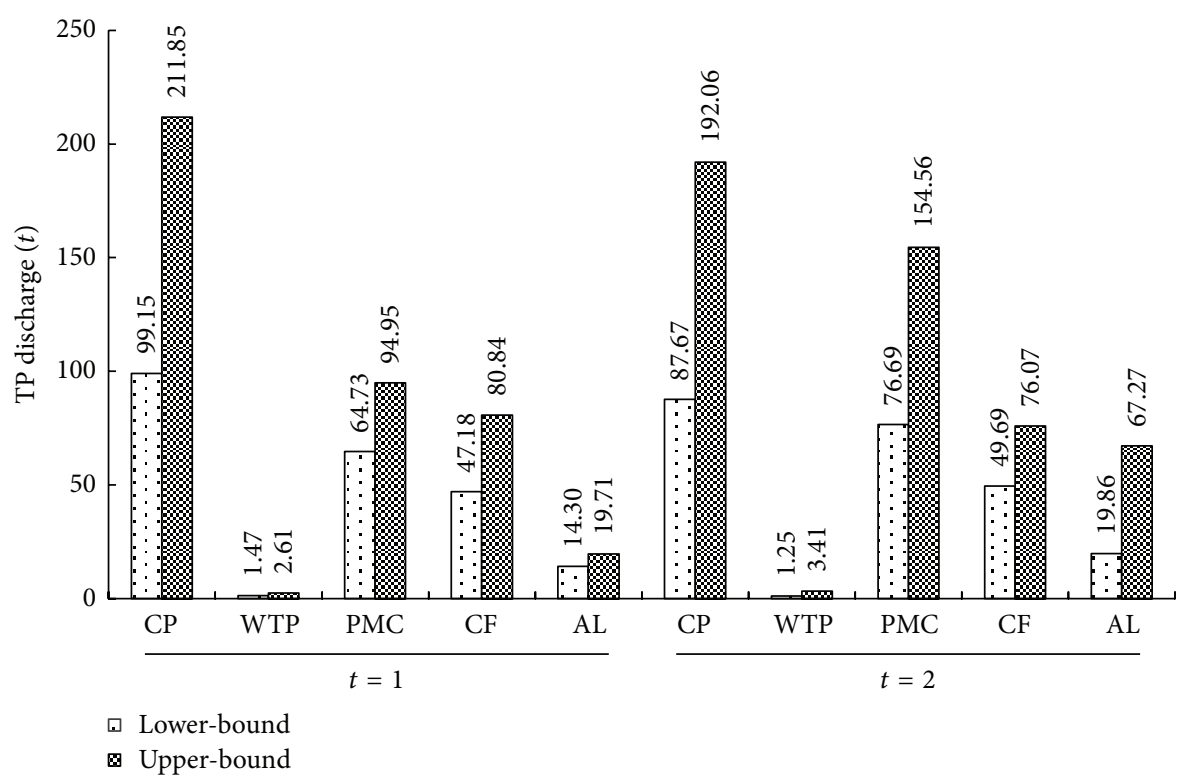

FIgURE 4: Solutions of TP discharge. Note: CP: chemical plant; WTP: wastewater treatment plant; PMC: phosphorus mining company; CF: crop farming; AL: agricultural life.

discharge from chemical plant would be $[99.15,211.85] \mathrm{t}$ in period 1 and $[87.67,192.06] \mathrm{t}$ in period 2 . Since the wastewater should be sluiced strictly according to the integrated discharge standards, the amount of TP discharge from WTPs would stay at a low level. Most of the TP would be from phosphorus-containing wastes (i.e., discharged directly and washed by rainfall). For nonpoint sources, the phosphorus pollutants from crop farming which can be generated though runoff and soil erosion (the latter would be a larger proportion) would be more than that from agricultural life. The amount of TP discharge from crop farming would be
$[47.18,80.84] \mathrm{t}$ in period 1 and $[76.69,154.56] \mathrm{t}$ in period 2 . This is associated with its high soil loss rate, low runoff, and low phosphorus concentration in the study area. Generally, TP discharge derives mainly from point sources, particularly from chemical plants. The results also indicate that the nitrogen pollutants would be generated by nonpoint sources (i.e., mainly from crop farming). TN discharge from citrus and tea can be neglected (i.e., nearly equal to aero). Figure 5 shows TN discharges from the other cropping areas. TN discharges from wheat and potato would be higher than those from rapeseed and alpine rice in period 1 ; TN discharges from 


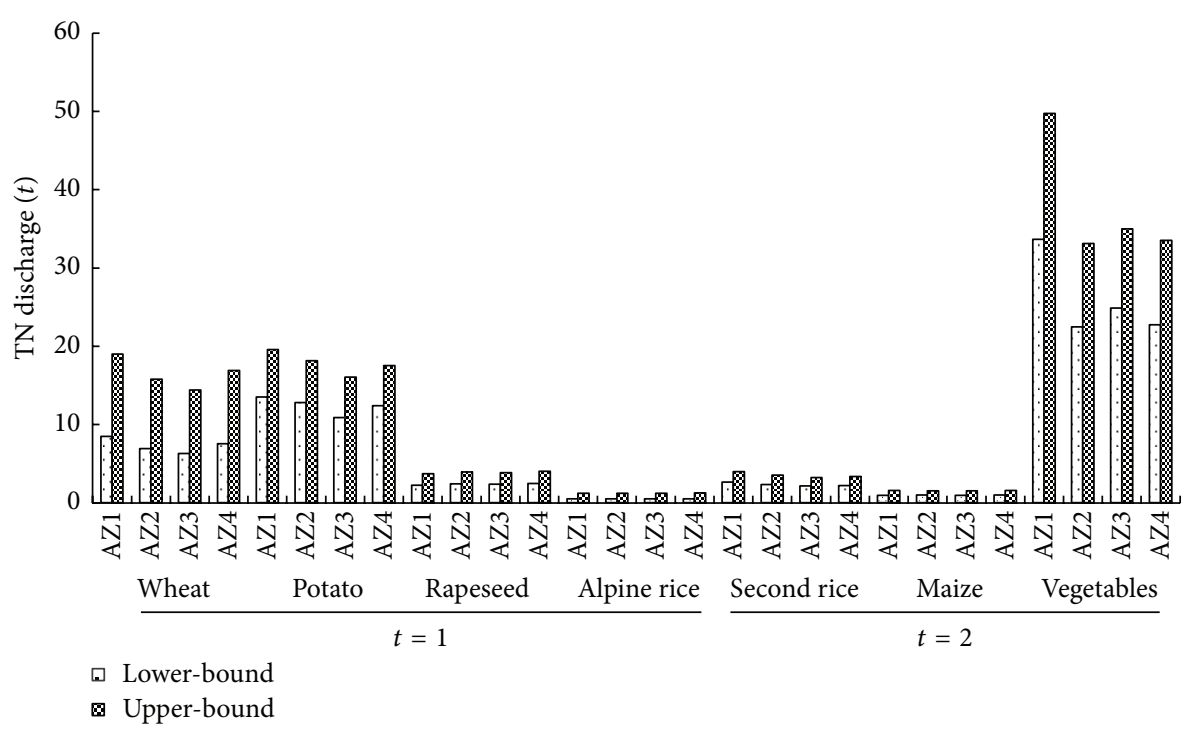

FIGURE 5: TN discharges from agriculture activities.

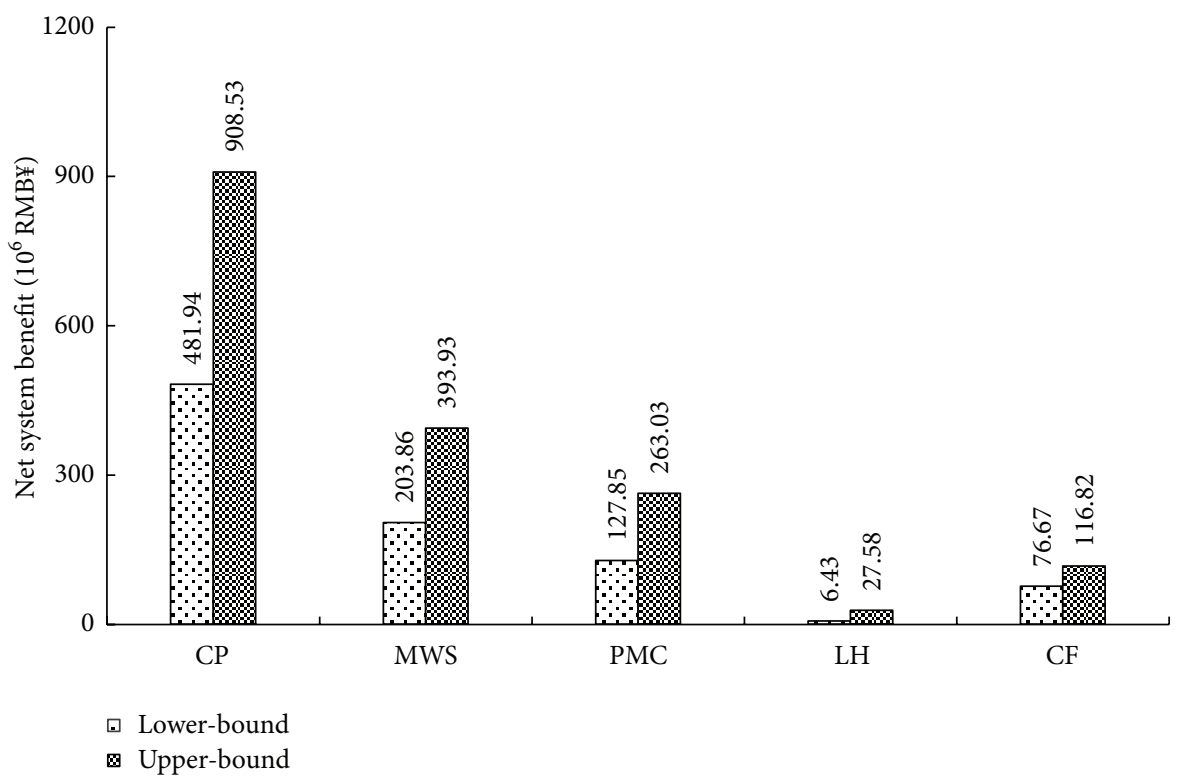

FIGURE 6: Net benefits from industrial and agricultural activities. Note: CP: chemical plant; MWS: municipal water supply; PMC: phosphorus mining company; CF: crop farming; LH: livestock husbandry.

vegetable would be higher than those from maize and second rice in period 2. This difference may be attributed to their planting areas, soil losses, runoff, and nitrogen concentration.

Net system benefit can be obtained from different industrial and agricultural activities, as shown in Figure 6. Chemical plants would be the major economic incoming source in the study area and could generate the highest revenue (RMB¥ $\left.[484.94,906.53] \times 10^{6}\right)$. Municipal water supply and phosphorus mining company would also make certain contribution to the economic development; their net benefits would be $\operatorname{RMB} ¥[203.86,393.93] \times 10^{6}$ and $\operatorname{RMB} ¥[127.85,263.03] \times$ $10^{6}$, respectively. Livestock husbandry would bring the lowest benefit. Such an industry-oriented pattern may be related to the abundant mineral resources (particularly phosphorus ore) which can generate high economic return. Agricultural activities would make less contribution to the local economic development due to its topography which is not suitable for cultivation in large parts.

\section{Conclusions}

In this study, an interval fuzzy credibility-constrained programming (IFCP) has been advanced for water quality management under uncertainty. This method integrates interval-parameter programming (IPP) and fuzzy credibilityconstrained programming (FCP) techniques within a general 
TABLE 5: Solutions for agricultural production.

\begin{tabular}{|c|c|c|}
\hline Crops and live stocks & \multicolumn{2}{|c|}{ Growth period } \\
\hline \multicolumn{3}{|l|}{ Crop area (ha) } \\
\hline Citrus & Whole year & {$[35.7,72.8]$} \\
\hline Tea & Whole year & {$[40.8,53.4]$} \\
\hline Wheat & Dry season & {$[1112.6,1894.2]$} \\
\hline Potato & Dry season & {$[1459.8,1620.3]$} \\
\hline Rapeseed & Dry season & {$[296.5,369.4]$} \\
\hline Alpine rice & Dry season & {$[206.5,393.2]$} \\
\hline Second rice & Wet season & {$[351.2,387.4]$} \\
\hline Maize & Wet season & {$[83.4,97.8]$} \\
\hline Vegetable & Wet season & {$[1745.2,1915.6]$} \\
\hline \multicolumn{3}{|l|}{$\begin{array}{l}\text { Manure application } \\
\left(10^{3} \mathrm{t}\right)\end{array}$} \\
\hline Citrus & Whole year & {$[10.4,19.3]$} \\
\hline Tea & Whole year & {$[8.2,11.7]$} \\
\hline Wheat & Dry season & {$[2.9,7.8]$} \\
\hline Potato & Dry season & {$[0.7,2.8]$} \\
\hline Rapeseed & Dry season & {$[4.1,4.7]$} \\
\hline Alpine rice & Dry season & {$[5.8,6.3]$} \\
\hline Second rice & Wet season & {$[5.2,5.7]$} \\
\hline Maize & Wet season & {$[0.8,1.1]$} \\
\hline Vegetable & Wet season & {$[1.2,1.4]$} \\
\hline \multicolumn{3}{|c|}{ Fertilizer application $(\mathrm{t})$} \\
\hline Citrus & Whole year & {$[0.7,1.0]$} \\
\hline Tea & Whole year & {$[804.3,893.6]$} \\
\hline Wheat & Dry season & {$[824.4,917.3]$} \\
\hline Potato & Dry season & {$[1023.4,1454.2]$} \\
\hline Rapeseed & Dry season & {$[2.4,3.6]$} \\
\hline Alpine rice & Dry season & {$[39.6,60.5]$} \\
\hline Second rice & Wet season & {$[292.7,316.3]$} \\
\hline Maize & Wet season & {$[0.2,0.3]$} \\
\hline Vegetable & Wet season & {$[1520.4,1632.1]$} \\
\hline \multicolumn{3}{|l|}{$\begin{array}{l}\text { Size of livestock } \\
\text { husbandry }\left(10^{3} \text { unit }\right)\end{array}$} \\
\hline Pig & Whole year & {$[0.121,35.462]$} \\
\hline Ox & Whole year & {$[0.688,0.813]$} \\
\hline Sheep & Whole year & {$[21.430,34.478]$} \\
\hline Domestic fowl & Whole year & {$[34.800,132.561]$} \\
\hline
\end{tabular}

optimization framework. Generally, the IFCP model has advantages in (1) handling uncertainties presented in terms of interval values and possibility distributions in the model, and (2) providing bases for determining optimal water quality management plans with desired compromises between economic benefits and environmental capacity-violation risks.

The developed model has been applied to a real-world case of planning water quality management in the Xiangxi River of the Three Gorges Reservoir Region. The objective is to maximize the net system benefit subject to the environmental requirements under uncertainty over the planning horizon. Pollutant discharges generated by various point and nonpoint sources were considered simultaneously. Interval solutions for production activities (i.e., industrial, municipal, and agricultural) and pollutant discharges (i.e., BOD, TP, and TN) under interval credibility levels have been generated by solving two deterministic submodels. The detailed results of related production scales and pollutant discharges can help identify desired water quality management schemes for developing the local economy in a sustainable manner. Some useful suggestions for the local economy development in a sustainable manner could be summarized: (i) advancing wastewater treatment technologies (e.g., tertiary treatment and depth processing technologies) to further improve pollutant removal efficiency; (ii) controlling the generation of phosphorus-containing wastes (from chemical plants and phosphorus mining companies) strictly in the production process and taking effective treatments and disposal measures to reach the goal of achieving TP abatement; (iii) taking control practices on soil erosion for reducing the transport of nitrogen and phosphorus pollutants to the river.

Although reasonable solutions and desired management policies have been obtained through the IFCP management model, there are still some extensive research works to be done. For example, the proposed IFCP method can deal with uncertainties expressed as fuzzy sets and interval numbers; however, the main limitations of the IFCP method remain in its difficulties in tackling uncertainties expressed as probabilistic distributions (stochastic uncertainties). Under such a circumstance, stochastic mathematical programming method is a suitable option to be introduced into the proposed IFCP method. Moreover, decision support regarding pollution management could be further provided by incorporating certain water quality simulation models into IFCP framework, which can effectively reflect dynamic interactions between pollutant loading and water quality.

\section{Acknowledgments}

This research was supported by the Natural Sciences Foundation of China (Grant nos. 51379075, 51225904, and 51109077), the 111 Project (B14008), and the Program for Innovative Research Team in University (IRT1127). The authors are grateful to the editors and the anonymous reviewers for their insightful comments and suggestions.

\section{References}

[1] P. Du, Y. P. Li, and G. H. Huang, "Inexact chance-constrained waste-load allocation model for water quality management of Xiangxihe River," Journal of Environmental Engineering, vol. 139, pp. 1178-1197, 2013.

[2] Y. P. Li and G. H. Huang, "Two-stage planning for sustainable water-quality management under uncertainty," Journal of Environmental Management, vol. 90, no. 8, pp. 2402-2413, 2009.

[3] Y. P. Li, W. Li, and G. H. Huang, "Two-stage inexactprobabilistic programming model for water quality management," Environmental Engineering Science, vol. 29, no. 7, pp. 713725, 2012. 
[4] Y. P. Li and G. H. Huang, "Fuzzy-stochastic-based violation analysis method for planning water resources management systems with uncertain information," Information Sciences, vol. 179, no. 24, pp. 4261-4276, 2009.

[5] X. S. Qin, G. H. Huang, G. M. Zeng, A. Chakma, and Y. F. Huang, "An interval-parameter fuzzy nonlinear optimization model for stream water quality management under uncertainty," European Journal of Operational Research, vol. 180, no. 3, pp. 1331-1357, 2007.

[6] B. Julien, "Water quality management with imprecise information," European Journal of Operational Research, vol. 76, no. 1, pp. 15-27, 1994.

[7] C.-S. Lee and C.-G. Wen, "Fuzzy goal programming approach for water quality management in a river basin," Fuzzy Sets and Systems, vol. 89, no. 2, pp. 181-192, 1997.

[8] P. P. Mujumdar and K. Sasikumar, "A fuzzy risk approach for seasonal water quality management of a river system," Water Resources Research, vol. 38, no. 1, pp. 51-59, 2002.

[9] H.-W. Chen and N.-B. Chang, "Decision support for allocation of watershed pollution load using grey fuzzy multiobjective programming," Journal of the American Water Resources Association, vol. 42, no. 3, pp. 725-745, 2006.

[10] S. Karmakar and P. P. Mujumdar, "Grey fuzzy optimization model for water quality management of a river system," Advances in Water Resources, vol. 29, no. 7, pp. 1088-1105, 2006.

[11] Y. P. Li, G. H. Huang, S. L. Nie, and D. W. Mo, "Intervalparameter robust quadratic programming for water quality management under uncertainty," Engineering Optimization, vol. 40, no. 7, pp. 613-635, 2008.

[12] X. H. Nie, G. H. Huang, D. Wang, and H. L. Li, "Robust optimisation for inexact water quality management under uncertainty," Civil Engineering and Environmental Systems, vol. 25, no. 2, pp. 167-184, 2008.

[13] S. Maeda, T. Kawachi, K. Unami, J. Takeuchi, T. Izumi, and S. Chono, "Fuzzy optimization model for integrated management of total nitrogen loads from distributed point and nonpoint sources in watershed," Paddy and Water Environment, vol. 7, no. 3, pp. 163-175, 2009.

[14] T. Y. Xu and X. S. Qin, "Solving water quality management problem through combined genetic algorithm and fuzzy simulation," Journal of Environmental Informatics, vol. 22, no. 1, pp. 39-48, 2013.

[15] M. Liu, G. X. Nie, M. Hu, R. F. Liao, and Y. S. Shen, "An interval-parameter fuzzy robust nonlinear programming model for water quality management," Journal of Water Resource and Protection, vol. 5, pp. 12-16, 2013.

[16] Y. M. Zhang and G. H. Huang, "Optimal water resource planning under fixed budget by interval-parameter credibility constrained programming," Engineering Optimization, vol. 43, no. 8, pp. 879-889, 2011.

[17] M. S. Pishvaee, S. A. Torabi, and J. Razmi, "Credibility-based fuzzy mathematical programming model for green logistics design under uncertainty," Computers and Industrial Engineering, vol. 62, no. 2, pp. 624-632, 2012.

[18] Y. P. Li, G. H. Huang, and S. L. Nie, "Optimization of regional economic and environmental systems under fuzzy and random uncertainties," Journal of Environmental Management, vol. 92, no. 8, pp. 2010-2020, 2011.

[19] R. Brouwer and C. De Blois, "Integrated modelling of risk and uncertainty underlying the cost and effectiveness of water quality measures," Environmental Modelling and Software, vol. 23, no. 7, pp. 922-937, 2008.
[20] Y. R. Fan and G. H. Huang, "A robust two-step method for solving interval linear programming problems within an environmental management context," Journal of Environmental Informatics, vol. 19, no. 1, pp. 1-9, 2012.

[21] Y. Xu, G. H. Huang, and T. Y. Xu, "Inexact management modeling for urban water supply systems," Journal of Environmental Informatics, vol. 20, no. 1, pp. 34-43, 2012.

[22] Y. Chen, S. Y. Cheng, L. Liu et al., "Assessing the effects of land use changes on non-point source pollution reduction for the Three Gorges Watershed using the SWAT model," Journal of Environmental Informatics, vol. 22, no. 1, pp. 13-26, 2013.

[23] L. He, G. Q. Wang, and C. Zhang, "Application of loosely coupled watershed model and channel model in Yellow River, China," Journal of Environmental Informatics, vol. 19, no. 1, pp. 30-37, 2012.

[24] Y. P. Li and G. H. Huang, "A recourse-based nonlinear programming model for stream water quality management," Stochastic Environmental Research and Risk Assessment, vol. 26, no. 2, pp. 207-223, 2012.

[25] L. Ye, Q.-H. Cai, R.-Q. Liu, and M. Cao, "The influence of topography and land use on water quality of Xiangxi River in three Gorges Reservoir region," Environmental Geology, vol. 58, no. 5, pp. 937-942, 2009.

[26] F. A. Deviney Jr., D. E. Brown, and K. C. Rice, "Evaluation of bayesian estimation of a hidden continuous-time markov chain model with application to threshold violation in water-quality indicators," Journal of Environmental Informatics, vol. 19, no. 2, pp. 70-78, 2012. 


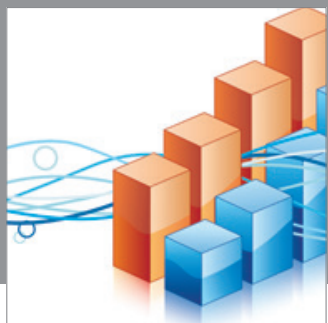

Advances in

Operations Research

mansans

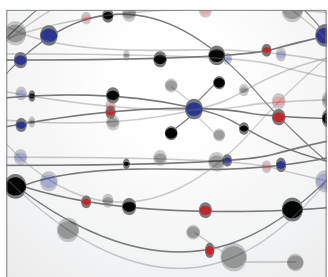

The Scientific World Journal
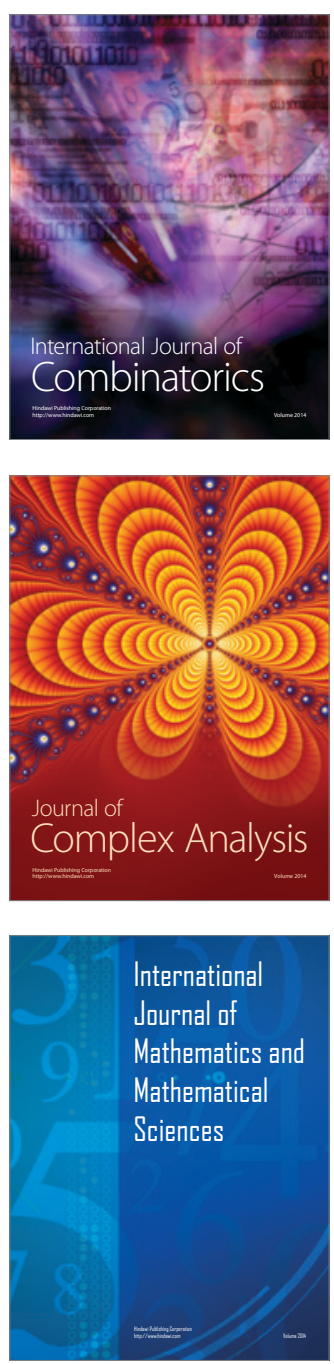
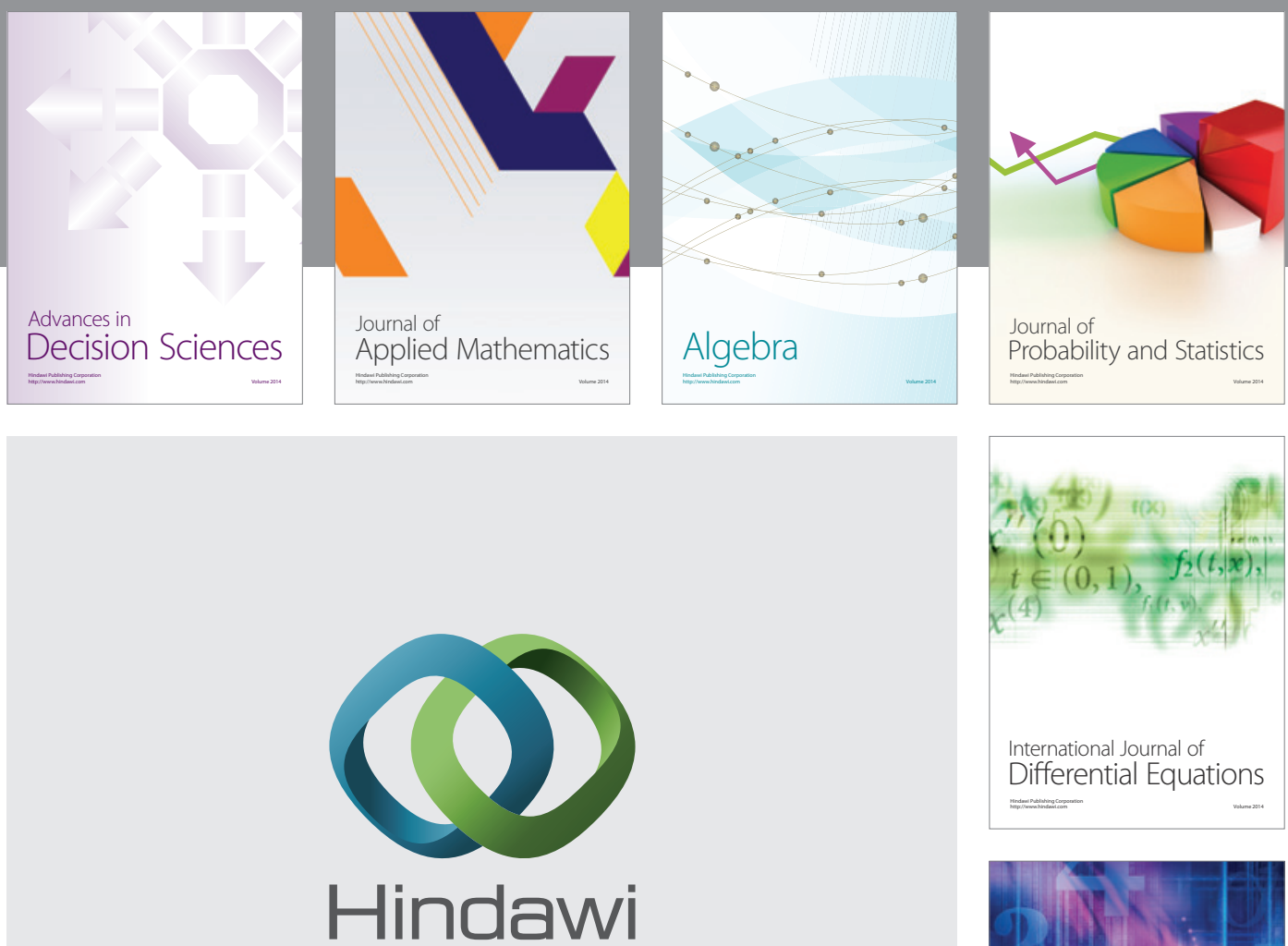

Submit your manuscripts at http://www.hindawi.com
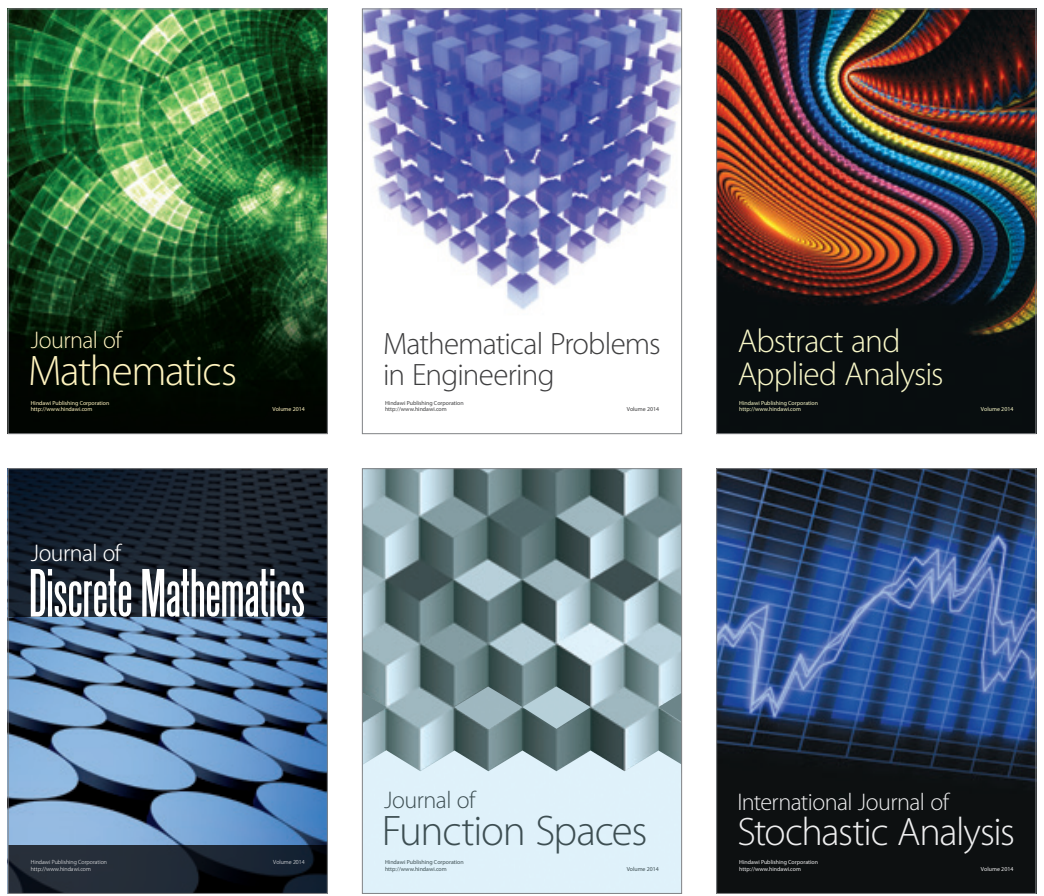

Journal of

Function Spaces

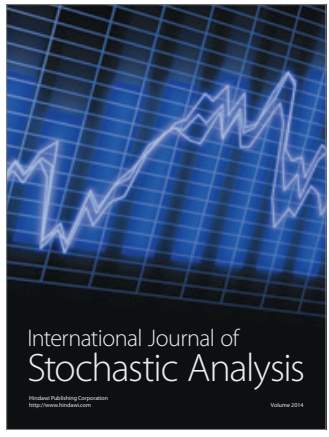

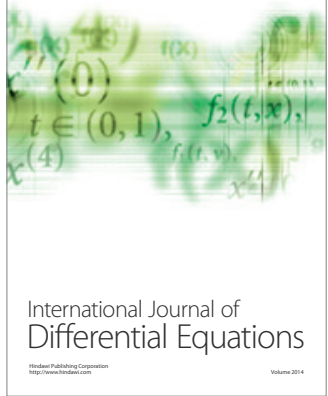
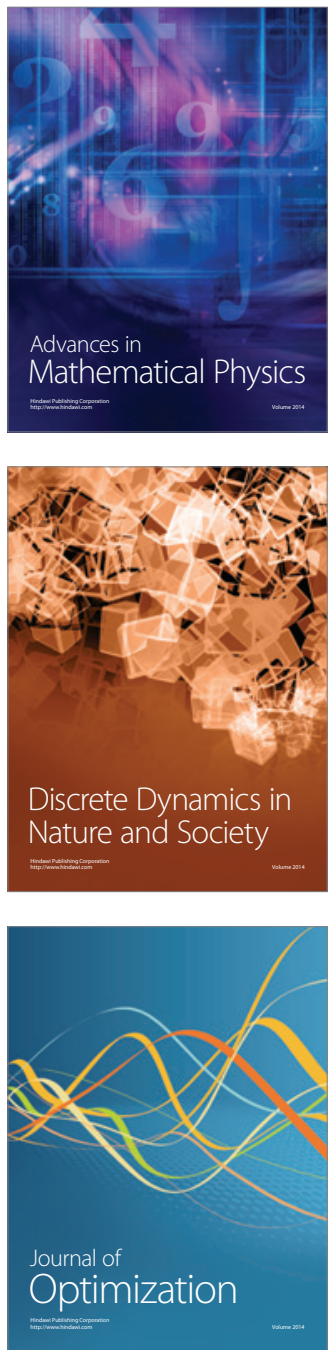